OPEN ACCESS

Edited by:

Hongyue Dang,

Xiamen University, China

Reviewed by:

Frank O'Neill Aylward,

University of Hawaii, USA

Karoline Faust,

KU Leuven/VIB, Belgium

*Correspondence: Mathias Milio

mathias.milici@helmholtz-hzi.de

${ }^{\dagger}$ Present Address: Johan Decelle,

Department of Isotope Biogeochemistry, Helmholtz Center for Environmental Research UFZ, Leipzig,

Germany

Specialty section: This article was submitted to Aquatic Microbiology,

a section of the journal

Frontiers in Microbiology

Received: 17 December 2015

Accepted: 18 April 2016

Published: 06 May 2016

Citation:

Milici M, Deng Z-L, Tomasch J, Decelle J, Wos-Oxley ML, Wang $H$, Jáuregui R, Plumeier I, Giebel H-A, Badewien TH, Wurst M, Pieper DH, Simon M and Wagner-Döbler I (2016) Co-occurrence Analysis of Microbial Taxa in the Atlantic Ocean Reveals High Connectivity in the Free-Living Bacterioplankton.

Front. Microbiol. 7:649. doi: 10.3389/fmicb.2016.00649

\section{Co-occurrence Analysis of Microbial Taxa in the Atlantic Ocean Reveals High Connectivity in the Free-Living Bacterioplankton}

\author{
Mathias Milici ${ }^{1 *}$, Zhi-Luo Deng ${ }^{1}$, Jürgen Tomasch ${ }^{1}$, Johan Decelle ${ }^{2,3 t}$, \\ Melissa L. Wos-Oxley ${ }^{4}$, Hui Wang ${ }^{1}$, Ruy Jáuregui ${ }^{4}$, Iris Plumeier ${ }^{4}$, Helge-Ansgar Giebel ${ }^{5}$, \\ Thomas H. Badewien ${ }^{5}$, Mascha Wurst ${ }^{5}$, Dietmar H. Pieper ${ }^{4}$, Meinhard Simon ${ }^{5}$ and \\ Irene Wagner-Döbler ${ }^{1}$ \\ ${ }^{1}$ Group Microbial Communication, Helmholtz-Center for Infection Research, Braunschweig, Germany, ${ }^{2}$ UMR 7144 - \\ Sorbonne Universités, UPMC Univ Paris 06, Roscoff, France, ${ }^{3}$ Centre National de la Recherche Scientifique, UMR 7144, \\ Roscoff, France, ${ }^{4}$ Group Microbial Interactions and Processes, Helmholtz-Center for Infection Research, Braunschweig, \\ Germany, ${ }^{5}$ Biology of Geological Processes, Institute for Chemistry and Biology of the Marine Environment, University of \\ Oldenburg, Oldenburg, Germany
}

We determined the taxonomic composition of the bacterioplankton of the epipelagic zone of the Atlantic Ocean along a latitudinal transect $\left(51^{\circ} \mathrm{S}-47^{\circ} \mathrm{N}\right)$ using Illumina sequencing of the V5-V6 region of the 16S rRNA gene and inferred co-occurrence networks. Bacterioplankon community composition was distinct for Longhurstian provinces and water depth. Free-living microbial communities (between 0.22 and $3 \mu \mathrm{m})$ were dominated by highly abundant and ubiquitous taxa with streamlined genomes (e.g., SAR11, SAR86, OM1, Prochlorococcus) and could clearly be separated from particle-associated communities which were dominated by Bacteroidetes, Planktomycetes, Verrucomicrobia, and Roseobacters. From a total of 369 different communities we then inferred co-occurrence networks for each size fraction and depth layer of the plankton between bacteria and between bacteria and phototrophic micro-eukaryotes. The inferred networks showed a reduction of edges in the deepest layer of the photic zone. Networks comprised of free-living bacteria had a larger amount of connections per OTU when compared to the particle associated communities throughout the water column. Negative correlations accounted for roughly one third of the total edges in the free-living communities at all depths, while they decreased with depth in the particle associated communities where they amounted for roughly $10 \%$ of the total in the last part of the epipelagic zone. Co-occurrence networks of bacteria with phototrophic micro-eukaryotes were not taxon-specific, and dominated by mutual exclusion ( $60 \%)$. The data show a high degree of specialization to micro-environments in the water column and highlight the importance of interdependencies particularly between free-living bacteria in the upper layers of the epipelagic zone.

Keywords: co-occurrence, bacteria-bacteria interactions, phytoplankton-bacteria interactions, next generation sequencing, Atlantic Ocean, bacterioplankton, 16S rRNA analysis, network analysis 


\section{INTRODUCTION}

Microorganisms play an essential role in all terrestrial and aquatic ecosystems. Their activity directly influences biogeochemical cycles of essential elements like carbon, nitrogen, and sulfur (Azam and Malfatti, 2007; Falkowski et al., 2008; Zehr and Kudela, 2011; Moran et al., 2012), and thus has a tremendous effect on the whole planet. In the ocean, prokaryotes (bacteria and archaea) are the most abundant living organisms, with an average of $5 \times 10^{5}$ cells per milliliter of sea water on the continental shelf but also in the upper $200 \mathrm{~m}$ of the oceanic water column (Whitman et al., 1998). However, this number refers only to the domains of bacteria and archaea without taking into account eukaryotic microorganisms (Caron et al., 2012; de Vargas et al., 2015), viruses (Suttle, 2005; Brum et al., 2015) or the ultra-small bacteria discovered recently (Brown et al., 2015). It is therefore easy to picture how crowded a milliliter of seawater is. The high number of microorganisms (archaea, bacteria, eukaryotes) and viruses per milliliter of seawater and their long evolutionary history (Cavalier-Smith, 2006) naturally forces the coexistence, interaction, and possibly co-evolution of microorganisms in the same spatial niche.

Within a milliliter of seawater, spatial niches are generally defined according to the pore size of the filter that is used to collect microorganisms. Filters with larger pore-size (generally larger than $3 \mu \mathrm{m}$ ) collect particles, micro-eukaryotes, and attached or ingested bacteria, while the truly planktonic or freeliving bacteria are typically captured on $0.1-0.22 \mu \mathrm{m}$ filters. However, the separation of the bacterioplankton according to the filter size does not strictly reflect bacterial lifestyle (Hartmann et al., 2013; Padilla et al., 2015), nevertheless, serial filtration represents a valid method that permits to investigate bacterioplankton communities from different size fractions of the plankton (Rusch et al., 2007; Sunagawa et al., 2015; Salazar et al., 2016). Bacteria collected on bigger size fractions ( $>3 \mu \mathrm{m}$ ) are presumably physically attached to particles and are often chemotactic (Stocker and Seymour, 2012). Free-living bacterial communities are dominated by cosmopolitan oligotrophic taxa with streamlined genomes such as the ubiquitous clade SAR11 (Morris et al., 2002; Grote et al., 2012; Morris R. M. et al., 2012; Giovannoni et al., 2014), while bacteria associated to particles composed of living and decaying phytoplankton and zooplankton as well as fecal pellets and cellular debris (Herndl and Reinthaler, 2013) have been described as copiotrophic. Those tend to have larger genomes with a broad spectrum of metabolic capabilities and are often cultivatable (Allen et al., 2013; Giovannoni et al., 2014). Moreover, many genes in their genomes are devoted to competition (Dang and Lowell, 2016).

Interactions within planktonic communities have been hypothesized to account for an important part of the observed diversity (Fuhrman et al., 2015). Examples for physical mutualistic symbioses in the ocean bacterioplankton have been discovered. For example, the uncultivated diazotroph cyanobacterium UCYN-A lives in an obligate symbiosis with prymnesiophyte (eukaryotic microalga), fixing and translocating nitrogen for the microalgae, which transfers photosynthetically fixed carbon in return (Thompson et al., 2012; Krupke et al., 2015). SAR11, the most abundant marine clade, is critically dependent on reduced sulfur compounds like DMSP (Dimethylsulfoniopropionate) provided by marine algae (Tripp et al., 2008) as well as on vitamins provided by other members of the microbial community (Carini et al., 2014). B vitamins and in particular B12 are essential cofactors of many enzymes, yet $<40 \%$ of the sequenced genomes reviewed in Sañudo-Wilhelmy et al. (2014) harbored the genetic machinery to fully synthesize cobalamin demonstrating a widespread auxotrophy for it.

It is now possible to resolve the community structure of marine plankton with a resolution high enough to construct co-occurrence networks of OTUs. Such networks can be used to develop hypotheses that can then be verified experimentally, as in the Tara Ocean study (Lima-Mendez et al., 2015) and also be used to simulate the effect of species extinction (Peura et al., 2015). Until now, co-occurrence networks have mainly been constructed from time-series data to observe the effect of season, daily variability, and plankton blooms. Time-series data from oceanographic long-term observatories (BATS, SPOT, HOT, and the English Channel) have shown an unexpected resilience of bacterioplankton communities that have largely recurrent composition in the seasonal cycle, while varying considerably on a daily timescale (Fuhrman et al., 2015). Topdown controls on the microbial community through viruses has been investigated (Chow et al., 2014), and from a timelagged relationship between upper and deeper water layers, it was hypothesized that the downward sinking of particles is one of the determinants of bacterioplankton community structure in deeper water layers (Cram et al., 2015b). Interestingly, environmental parameters, although possibly inducing phytoplankton blooms, were negligible in determining plankton community structure during the weeks that the succession induced by the bloom continued, suggesting that interactions within the community played a much more important role than previously thought (Needham and Fuhrman, 2016). Similarly, the analysis of the Tara Oceans dataset demonstrated that environment and geography explained up to $18 \%$ of community variation. Using a random forest approach it was shown that $95 \%$ of the models based on OTU composition alone were more accurate in explaining variation than models incorporating additionally environmental data (Lima-Mendez et al., 2015).

As far as we know the Tara Oceans study is the only one that uses such a holistic network approach on samples covering a geographical range in the ocean, and not a timeseries on a fixed location. The network was useful in discovering new and globally important interactions (Lima-Mendez et al., 2015) and was also used to start quantifying and predicting the biological carbon pump (Guidi et al., 2016). Here, we used the network approach to infer co-occurrences of bacteria and photosynthetic micro-eukaryotic in the Atlantic Ocean. The samples were derived from 27 stations across almost the entire Atlantic Ocean $\left(51^{\circ} \mathrm{S}-47^{\circ} \mathrm{N}\right)$. For each station, the epipelagic zone $(20-200 \mathrm{~m})$ was sampled with an average of five depths per station. Water samples were fractionated into three size classes. Thus, we were able to compare free-living to particle attached communities throughout the transect. Sinking particles export biomass from the euphotic zone to the deep 
ocean and thus have an important role for the biological carbon pump (Herndl and Reinthaler, 2013). Community composition was investigated by Illumina sequencing of the V5-V6 region of the 16S rRNA gene of bacteria and of algal chloroplasts, thus providing a fairly extensive picture of the cooccurring phototrophic microalgae. We have previously reported a taxonomy independent analysis of the data, based on OTU assignment only. We could show that alpha-diversity does not increase in the tropical regions and has a non-linear relationship with temperature (Milici et al., 2016b). The biogeographical parameters shaping beta-diversity were subsequently analyzed, and we could show that the distance-decay relationship does not hold on a global scale; communities separated by almost $12,000 \mathrm{~km}$ across the ocean were most similar to each other; Longhurstian province, depth within the epipelagic zone and the composition of co-occurring micro-eukaryotes accounted for a large fraction of beta-diversity (Milici et al., 2016a). Interestingly, all of those findings applied similarly to bacteria from all three size fractions of the bacterioplankton, independent from the composition of the communities themselves. Here we now describe the taxonomic composition of those samples, showing that Longhurstian oceanographic provinces and depth layers of the epipelagic zone of the Atlantic Ocean enrich for different taxa. Microbial taxa living on particles were also clearly different from those of free-living ones. Certain lineages from almost all phyla detected here were enriched on particles, and certain phyla were exclusively found on them. We then combined the 369 communities in our study according to depth and calculated co-occurrence networks for free-living and particleassociated communities. We found a much higher number of co-occurrences in the free-living communities when compared to the particle associated communities.

\section{MATERIALS AND METHODS}

\section{Sampling}

Samples were collected during the cruise ANT-28/5 (10 April-15 May 2012 with RV Polarstern) at 27 stations across a latitudinal transect in the Atlantic Ocean $\left(51^{\circ} \mathrm{S}-47^{\circ} \mathrm{N}\right)$ (Figure 1A). At all stations, samples were consistently collected from five depths of the epipelagic zone: $20,40,60,100$, and $200 \mathrm{~m}$; seven samples were taken $\pm 10 \mathrm{~m}$ from the designated depths and additional eight samples were taken from intermediate depths (Table S1). To be able to analyze those samples together with the others, all samples were grouped according to five depth layers: 20, 40, 50-80, 85-120, and 140-200 m (Table S1). Water samples were fractionated using serial filtration as described (Milici et al., 2016b). Three size fractions of the plankton were therefore obtained: FL (free-living) for bacteria collected on the $0.22 \mu \mathrm{m}$ membranes, SPA (small particle associated) for bacteria collected on the $3 \mu \mathrm{m}$ membranes, and LPA (large particle associated) for bacteria collected on the $8 \mu \mathrm{m}$ membranes.

DNA extraction and Illumina sequencing were performed as described (Milici et al., 2016b) and the raw data can be accessed at the ENA database (European Nucleotide Archive) BioProject ID: PRJEB11493.

\section{Taxonomic Classification}

Taxonomic classification was assigned using SINA aligner (version 1.2.11) (Pruesse et al., 2012) employing the reference database SILVA (119 NR) (Pruesse et al., 2007). The OTUs were aligned and classified against a maximum of 100 sequences that had a minimum of $97 \%$ similarity with the query sequence, using the lowest common ancestor method (LCA). The retrieved results were sorted for further analysis and processed in the following way: all the OTUs assigned to archaea or "unclassified" were excluded from the dataset and not considered further, since in silico analysis of the primer coverage revealed that only $18.2 \%$ of the archaeal sequences present in the SILVA database (123 NR) matched the primers used here. Sequences assigned to "chloroplast" were excluded from the bacterial table and analyzed separately with the PhytoREF database (Decelle et al., 2015) with BLAST version 2.2.28 (Camacho et al., 2009). All reads that had a similarity below $95 \%$ to known 16S sequences were excluded from the dataset. Results of the SINA classification were checked with BLAST (Camacho et al., 2009) version 2.2.28 against the SILVA 119 NR database (Pruesse et al., 2007). Some reads could be assigned only at the domain or phylum level with SINA (Table S2). For those ambiguous sequences a manual curated taxonomical assignment was performed (Figure S1). We first performed BLAST for the sequences against the SILVA database in order to understand whether the mis-classification was due to the absence of a reference or to misclassified sequences in the database. We found sequences that were assigned to two contrasting phylogenetic lineages of the domain bacteria (e.g., OTU_2_FL had 100\% similarity both with a Prochlorococcus and OM1 clade sequence). Based on these results we downloaded a reference dataset constructed according to the BLAST results employing the SILVA database. We constructed alignments with MUSCLE and built phylogenetic trees with MEGA 6 using Neighbor-Joining method (Tamura et al., 2013).

Because of the difference in gene copy number across the different algae and bacterial lineages, read counts of $16 \mathrm{~S}$ rRNA genes cannot be used to infer cell abundance. Here, we therefore report relative comparisons only using the term "relative abundance." The taxonomic information and relative abundances of the OTUs identified in this study are reported in Table S3.

\section{Statistical Analysis and Network Analysis}

Statistical analyses were performed with PRIMER (v.7.0.6, PRIMER-E, Plymouth Marine Laboratory, Plymouth, UK; Clarke and Gorley, 2015), with the add on PERMANOVA+ (v. 1.0.6 PRIMER-E, Plymouth Marine Laboratory, Plymouth, UK; Anderson et al., 2006) and the statistical program R (https:// www.r-project.org/, v. 3.0.1) with the library vegan: Community Ecology Package (v. 2.0-8). Rarefaction analysis was performed in $\mathrm{R}$ with library vegan, in order to assess if the sequencing effort was sufficient to investigate bacterial communities (Figure 1B). To infer correlations between OTUs and OTUs and environmental parameters, we first removed OTUs with a relative abundance below $0.1 \%$ of the total number of reads. We also removed all samples that had $<7500$ reads. Rare OTUs and samples with low 


\section{A}

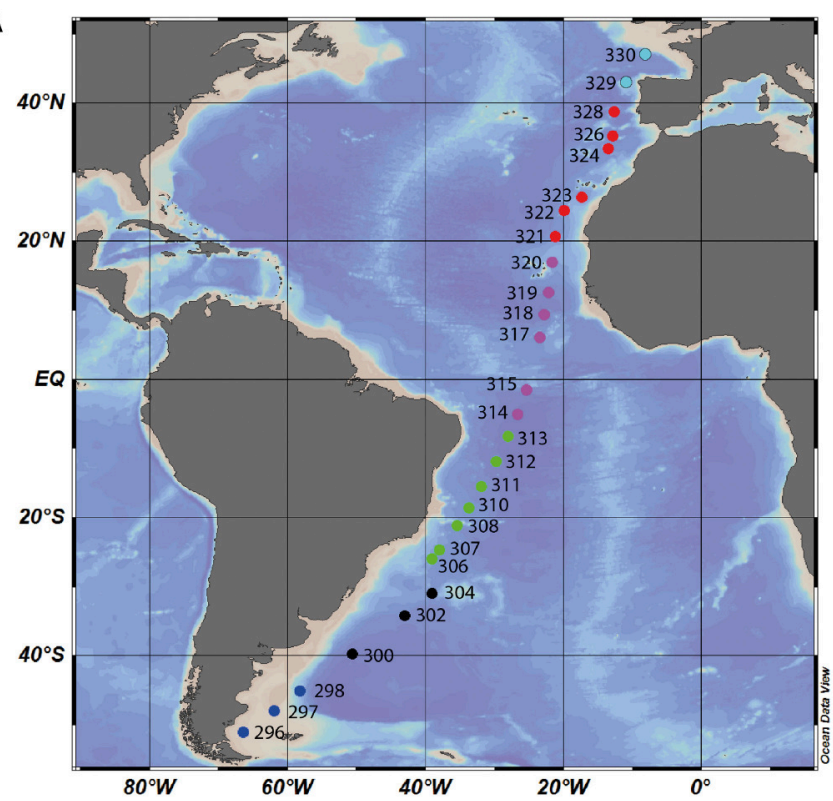

- FKLD - Southwest Atlantic Shelves Province

- BRAZ - Brazil Current Coastal Province

- SATL - South Atlantic Gyral Province

- WTRA - Western Tropical Atlantic Province

- NAG - North Atlantic Gyral Province

- NADR - North Atlantic Drift Province

B
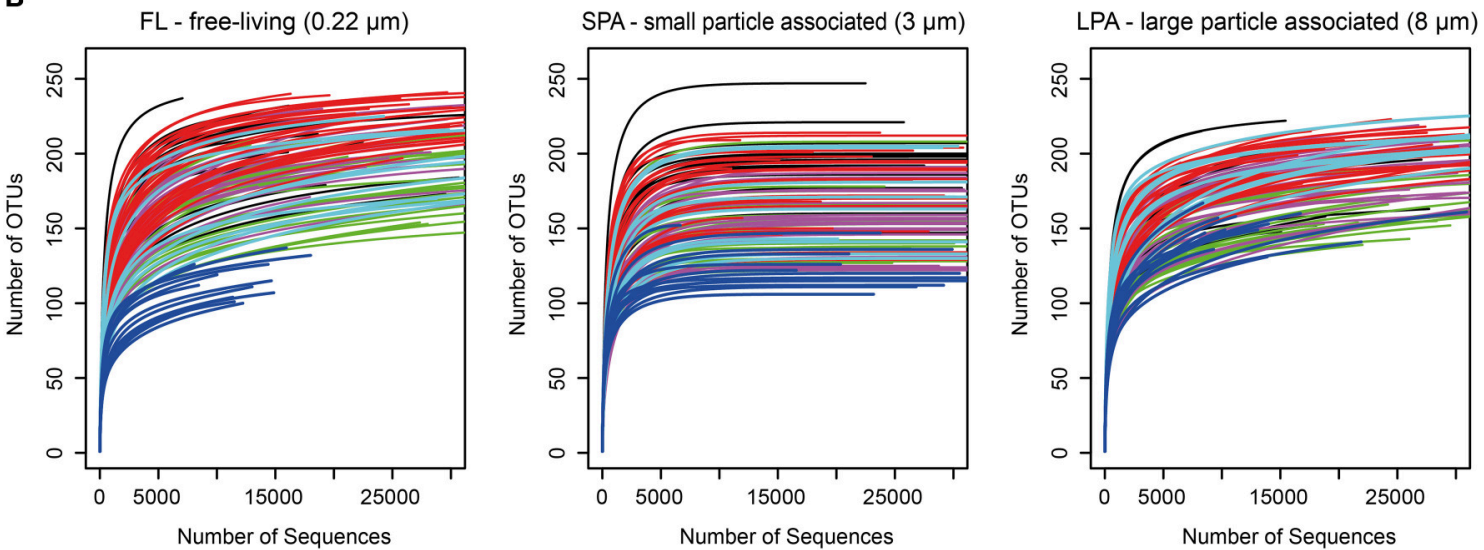

FIGURE 1 | Sampling sites and rarefaction analysis. (A) Sampling sites across the Atlantic Ocean; for each station the original sampling ID is reported. (B) Rarefaction analysis for the three size fractions of bacterioplankton. The number of sequences per sample was limited to 30,000 sequences, the original raw data can be found in Table S3. For both panels color code distinguishes the six oceanographic provinces.

sequencing depth might cause artifacts in the network analysis (Berry and Widder, 2014; Ju et al., 2014). Subsequently sample size for each of the three size fraction of the plankton was rarefied to $8,709,10,125$, and 7,780 sequences per sample in FL, SPA, and LPA respectively. The cumulative species dominance is shown in Figure S2.

Co-occurrences were then calculated with SparCC (Friedman and Alm, 2012) for each size fraction of the plankton and depth layer (20, 40, 50-80, 85-120, and 140-200 m) separately. Ten iterations were used to estimate the median correlation of each pairwise and the statistical significance of the correlations was calculated by bootstrapping with 500 iterations. Correction for multiple-testing of the $P$ values was performed in $\mathrm{R}$ according to Benjamini-Hochberg method. Correlations were then sorted for statistical significance $(p<0.05)$ and $R> \pm 0.6$.
In order to account for the effect of indirect taxon edges driven by environmental parameters, methods from LimaMendez et al. (2015) were applied. For each taxon-environment union network, node triplets consisting of two taxa and one environmental parameter were identified in R. For each triplet, interaction information II was computed as II $=\mathrm{CI}(\mathrm{X}, \mathrm{Y} \mid \mathrm{Z})-$ $\mathrm{I}(\mathrm{X}, \mathrm{Y})$, where $\mathrm{CI}$ is the conditional mutual information between taxa $\mathrm{X}$ and $\mathrm{Y}$ given environmental parameter $\mathrm{Z}$, and $\mathrm{I}$ is the mutual information between X and Y. CI and I were estimated by using minet (Meyer et al., 2008). Taxon edges in environmental triplets were considered indirect when II $<0$ and within the 0.05 quantile of the random II distribution obtained by shuffling environmental vectors (500 iterations). Furthermore, we checked if the triplets selected from the mutual information analysis were consistent in terms of sign patterns, as in Lima-Mendez et al. 
(2015). The original networks are reported in Table S4, and, the number of removed correlations is reported in Table S5.

To investigate associations between bacterial communities and photosynthetic micro-eukaryotes retrieved from the $8 \mu \mathrm{m}$ filter, correlations were inferred with SparCC (Friedman and Alm, 2012). For this analysis, samples belonging to the last depth layer $(140-200 \mathrm{~m})$ as well as those with $<150016 \mathrm{~S}$ rRNA chloroplast sequences were excluded. Correction for multiple-testing of the $P$ values was performed in $\mathrm{R}$ according to Benjamini-Hochberg method. Correlations were sorted for statistical significance $(p<0.05)$ and $R> \pm 0.6$. Networks were explored with Cytoscape, v 3.1.1 (Shannon et al., 2003). Topological parameters were calculated in Cytoscape with the tool network analyzer (Assenov et al., 2008).

\section{RESULTS}

\section{Overview of Sequencing Results and Primers Coverage}

A total of 13.6 million reads were generated and roughly 11.2 million reads were affiliated to bacteria with a total of 259 OTUs for the FL (free-living bacteria, 0.22-3 $\mu \mathrm{m}$ ), 269 OTUs for the SPA (small particle associated bacteria, 3-8 $\mu \mathrm{m}$ ), and 236 OTUs for the LPA (large particle associated bacteria $>8 \mu \mathrm{m}$ ) (Table S3). The average number of bacterial sequences per sample was similar for the three different communities: FL 27,552 $\pm 12,662$, SPA 33,328 $\pm 10,586$, and LPA 26,504 \pm 12,446 (Table S3), despite the presence of photosynthetic eukaryotes especially in SPA and LPA. Rarefaction analysis showed that the vast majority of samples approached the plateau indicating a good sampling effort (Figure 1B). In silico test of primers coverage (F807 and R1050) (Bohorquez et al., 2012; Klindworth et al., 2013) showed a good coverage $(86.4 \%)$ of bacterial lineages included in the SILVA database (version 123, NR). Taxonomic classification of the bacterial sequences showed that the majority of the OTUs (59-69\%) could be affiliated at the order level, between 35 and $42 \%$ of OTUs could be affiliated to a family, and $16-24 \%$ were assigned to a genus (Table S6).

Because the primers used were universal for the prokaryotic small subunit RNA gene, they inevitably amplified also the plastidial 16S rRNA gene of eukaryotic microalgae. They were not found in the FL community (confirming the efficiency of the filtration), but amounted to $\sim 6 \%$ in the SPA community and were termed SP (small phytoplankton) and $\sim 21 \%$ in the LPA community and were termed LP (large phytoplankton). Seven different classes of microalgae could be identified (Table S3). An average of $1,094 \pm 1,189$ sequences for SP and 7,345 $\pm 10,504$ for LP were generated. In silico analysis of the primer coverage of the marine photosynthetic eukaryotes (terrestrial lineages were excluded) included in the PhytoREF (Decelle et al., 2015) database revealed that primer sequences perfectly matched (no mismatch) $68 \%$ of the reference sequences (Table S7) and had one mismatch with $88 \%$ of the reference sequences (data not shown). Primers coverage differed for the various taxa; e.g., it was high for diatoms (92\%) but low for haptophytes (8\%) (Table S7). Although abundant, photosynthetic dinoflagellates are also under-represented in the reference database PhytoREF because of their specific plastidial genome organization (Decelle et al., 2015). These biases have to be taken into account when interpreting the data.

\section{Taxonomic Composition of the Bacterioplankton}

The relative abundance of the major marine groups of bacteria in the five depth layers of the epipelagic zone across the six oceanographic provinces covered in the cruise showed taxon specific distribution patterns according to filter size, province, and depth (Figure 2). Typical free living bacteria (clades SAR11, SAR86, SAR406, and SAR202) dominated the FL size fraction. By contrast, the LPA size fraction was dominated by Bacteroidetes, Actinobacteria, and Gammaproteobacteria other than SAR86. Planctomycetes and Verrucomicrobia were, absent in the FL community but found, in the SPA and LPA communities. Alphaproteobacteria other than SAR11 were found in both the FL and SPA size fraction at similar abundance, but represented a minor percentage in the LPA fraction.

Each province represented a unique environment in which specific taxonomic groups were enriched, depleted, or absent, with some general patterns that were conserved across the three size classes (FL, SPA, and LPA). Actinobacteria showed a transition from the South to the North of the transect. While in the FKLD and the BRAZ provinces they were enriched in the FL community, they became more abundant in the SPA size fraction from the SATL province onward. Bacteroidetes were more abundant in the two marginal provinces, where they reached the highest relative abundances. Cyanobacteria instead increased toward the equator with a peak in the SATL province, while Actinobacteria were more abundant in the WTRA province. SAR11 accounted for almost $30 \%$ of the total community in the NAG province.

Depth-related abundance patterns were also observed for most of the marine groups. For example, Cyanobacteria were depleted below $85 \mathrm{~m}$ except in the SPA community. SAR11 and SAR86 were more abundant above $120 \mathrm{~m}$, while SAR406 and SAR202 were more abundant below $85 \mathrm{~m}$. Gammaproteobacteria other than SAR 86 accounted for more than $30 \%$ of all reads in the FKLD and WTRA province at 140-200 $\mathrm{m}$.

Figure 3 shows the relative proportion of reads on the three types of filters analyzed here for the same phylogenetic groups. More than half of all Bacteroidetes reads were found in the LPA community in all depths and provinces. Actinobacteria appeared to be heterogeneous, with more than $50 \%$ of reads in the FL community of the FKLD, BRAZ, and SATL province, but relatively even distribution between all three filter sizes in the other three provinces. About $75 \%$ of all SAR11 reads were found in the FL community; the remaining reads were mostly found in the SPA and some in the LPA community. Although SAR11 is a typical planktonic organism, it was previously detected in relatively high abundance in the particle attached fraction (Mohit et al., 2014). It is unclear if this is an artifact of the filtration procedure or a real biological finding, e.g., caused 


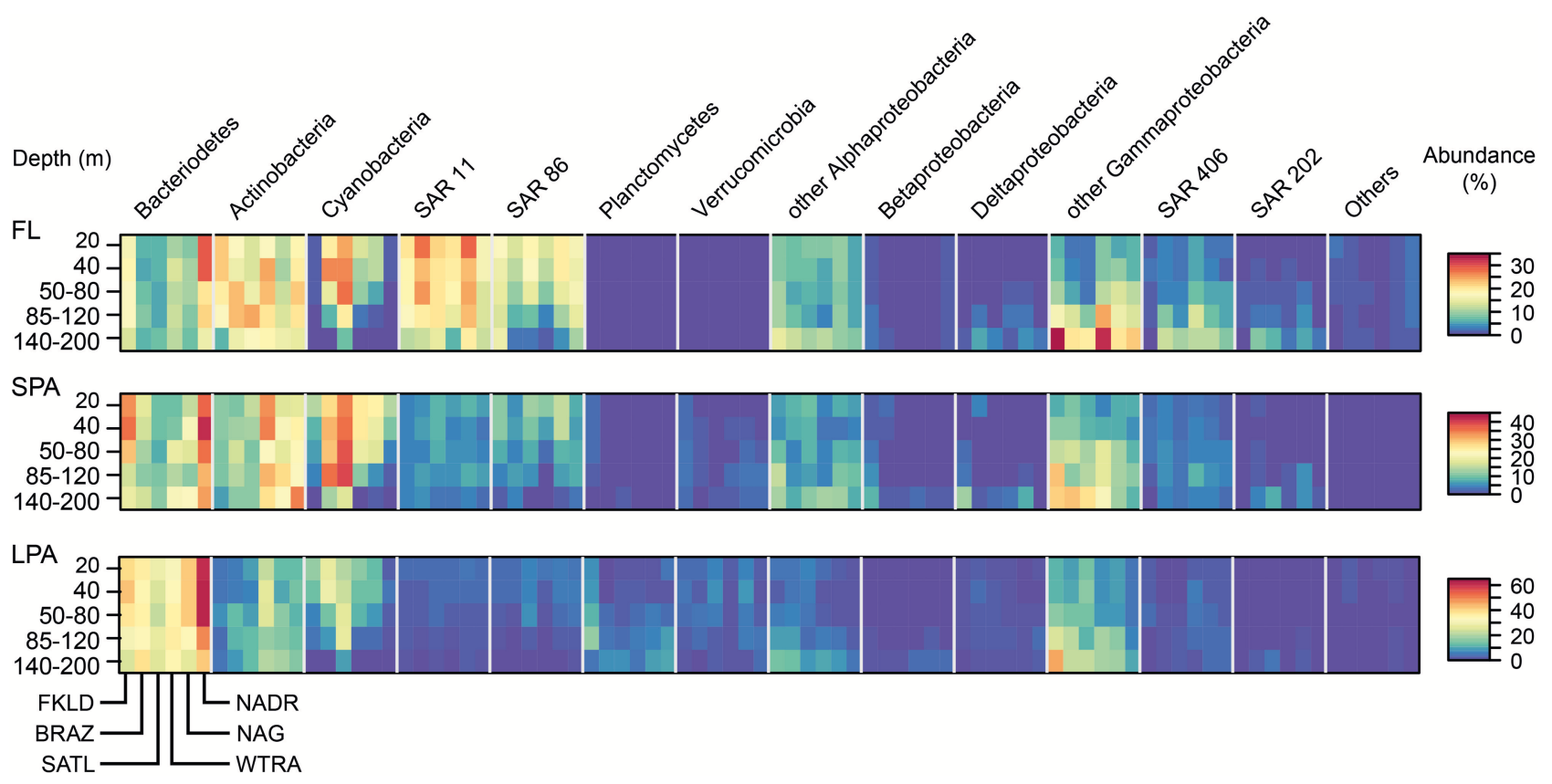

FIGURE 2 | Relative abundance of marine taxonomic groups of bacteria for the six oceanographic provinces across the whole photic zone and for three different size fractions. The relative abundances of the main taxonomic groups (expressed in percent of total) were averaged for each province for all the five depth layers. OTUs were combined at the phylum level for most of the taxonomic groups, only Proteobacteria were grouped at the class level as same in all other figures. Important marine clades are shown separately because of their strong contribution to the bacterial communities. The remaining groups or unclassified bacterial OTUs are shown as "Others." The heat map for each taxonomic group shows the five depth layers on the y-axis from the top to the bottom, and the six oceanographic provinces on the x-axis from South to North. Each taxonomic group is therefore composed of a block consisting of six times five rectangles, encompassing the provinces and depth layers, respectively. The three size fractions of the bacterioplankton (FL, SPA, LPA) are shown in three separate panels from top to bottom.

\begin{tabular}{|c|c|c|c|c|c|}
\hline $\mathrm{FL}$ & $20 \mathrm{~m}$ & $40 \mathrm{~m}$ & $50-80 m$ & $85-120 m$ & $140-200 m$ \\
\hline $\begin{array}{l}\text { SPA } \\
\text { LPA }\end{array}$ & 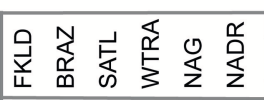 & 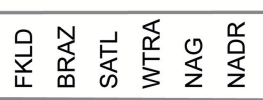 & 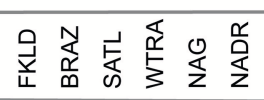 & 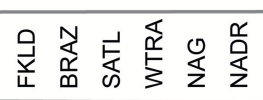 & 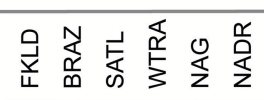 \\
\hline Bacteriodetes & 190000 & 10000 & 1400 & 1400 & $19 \theta 00$ \\
\hline Actinobacteria & 10000 & 1000 & 0000 & 10000 & 0000 \\
\hline Cyanobacteria & 0000 & 0000 & 000 & $\theta \rightarrow 00$ & 1000 \\
\hline SAR 11 & $P Q$ & $\theta Q$ & 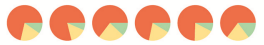 & DO & $Q Q$ \\
\hline SAR 86 & 100000 & 100000 & 10000 & 100 & 8 \\
\hline Planctomycetes & 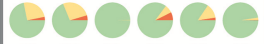 & C & C & C & 3 \\
\hline Verrucomicrobia & 00 & O & 000000 & 00000 & 000000 \\
\hline other Alphaproteobacteria & 10000 & - 900 & 00000 & 1000 & 10000 \\
\hline Betaproteobacteria & $\theta-000$ & $\theta \theta \theta \theta$ & 14000 & 10000 & 100000 \\
\hline Deltaproteobacteria & 4 & & 000000 & 100000 & 10000 \\
\hline other Gammaproteobacteria & 10000 & 10000 & 100 & 100 & 10000 \\
\hline SAR 406 & 10000 & 1000 & 10000 & 100000 & คคคด \\
\hline SAR 202 & $P Q P O$ & $P Q$ & $\theta$ & PQPO & 80 \\
\hline Others & 100000 & 10 & 10000 & 10000 & 19000 \\
\hline
\end{tabular}


by mixotrophic eukaryotes, including microalga cells ingesting SAR11 (Hartmann et al., 2013).

SAR86, SAR406, and SAR202 showed a similar pattern, however the fraction of particle associated bacteria was higher for those clades. By contrast, nearly all of Planctomycetes and Verrumicrobia were found in the LPA or SPA size fraction. These groups are known for their sessile lifestyle (Pizzetti et al., 2011; Freitas et al., 2012). Reads from Alphaproteobacteria other than SAR11 were found on all filter sizes with varying percentage, in accordance with the different lifestyles and abundance patterns of globally distributed uncultivated clades (Voget et al., 2015) and algae-associated copiotrophs (Wagner-Döbler et al., 2010). The same holds true for Beta, Delta- and Gammaproteobacteria (other than SAR86) which are comprised of physiologically diverse species.

We then investigated relative abundance patterns at the level of clade or, if possible, genus, across depths, and provinces on the three filters (Figure 4, Figures S3, S4). Here, the differences in community composition along the oceanographic provinces and water column were even more striking. For example, Planktomarina sp. a Rhodobacteraceae (Giebel et al., 2013) was found almost exclusively in the FKLD province in the FL community. Acinetobacter was more abundant in the FKLD province and still found in the BRAZ province but almost absent throughout the rest of the transect. Thalassospira sp. was only found in the FKLD province and Vibrio sp. was more abundant in the WTRA province. The groups NS10 and NS7 were mainly represented in the FKLD and NADR provinces. Many more examples can be retrieved from the data, supporting the provincialism of bacterioplankton communities despite the absence of dispersal limitation across provinces (Milici et al., 2016a). The same is true for the clear depth related distribution of most microbial taxa. Alcanivorax sp., a known hydrocarbon degrading bacterium (Kostka et al., 2011), was found at high densities in the deeper part of the photic zone (140-200 m), accounting for up to $25 \%$ of all reads in the SATL and FKLD provinces. Several other taxonomic groups showed a gradual increase in relative abundance toward the deeper layers of the photic zone, e.g., Rhodococcus sp., Brevudimonas sp., and ZD0417, as well as most of the Gammaproteobacteria.

Beside regional patterns driven by provincialism and bathymetric stratification also widespread and abundant members of the community were observed. SAR 11 and SAR86 were the most abundant taxa in the FL community in almost all provinces and depths. Interestingly, the relative abundance of the OM1 clade (Candidatus Actinomarina minuta; Ghai et al., 2013) was extremely high $(\sim 20 \%)$ throughout the whole transect. Clade AEGAN169 was also ubiquitous, but had a low abundance.

For the particles associated communities the shift in the taxonomic composition was even more pronounced at the genus and clade level. We observed several examples of specific lineages which were exclusively found in the SPA and LPA community like the NS7, NS9, and NS10 lineages of the Bacteroidetes. Dinoroseobacter shibae, a roseobacter which has been isolated from dinoflagellate cultures (Wagner-Döbler et al., 2010), was found in the SPA community of the FKLD province. Within the Deltaproteobacteria, some lineages were found exclusively on the particles like the OM27 and GR-WP33-58 clades/groups. Similarly, lineages within the Verrucomicrobia (e.g., Arctic97B4 marine group and Roseibacillus sp.) and the Planctomycetes (e.g., Blastopirellula sp. and Planctomyces sp.) were found exclusively on particles. Many other examples of taxonomic groups specifically enriched on one of the size fractions of the bacterioplankton can be retrieved from Figures S3, S4. Those results suggest that particles select for specific microbial communities and require genomic traits present in various microbial lineages.

\section{Distribution and Taxonomic Composition of Photosynthetic Eukaryotes}

The sequences from the plastidial 16S rRNA genes of photosynthetic eukaryotes obtained in this study were analyzed using the reference database PhytoREF (Decelle et al., 2015) and have unambiguously been assigned with high percentage similarity (from 95 to 100\%) to reference sequences (Table S3). In the LP communities $(>8 \mu \mathrm{m})$ seven classes of eukaryotic microalgae were identified, from which Bacillariophyceae (diatoms) and Prymnesiophyceae (haptophytes) were numerically the most prevalent (Figure 5) and showed a clear biogeographical pattern. Bacillariophyceae were more represented in the marginal provinces (FKLD and NADR) with strong depletion in relative abundances in the more oligotrophic SATL province. By contrast, Prymnesiophyceae were the most abundant group from the BRAZ to the NAG province with peaks in the BRAZ and SATL province. Pelagophyceae and Dictyophyceae were very rare in the FKLD and NADR provinces and more abundant in the BRAZ and SATL province. Cryptophyceae showed an opposite pattern with an enrichment in the FKLD and NADR provinces and were almost absent throughout the rest of the transect. Moreover, photosynthetic eukaryotes showed patterns related to depth: Prymnesiophyceae for instance increased in the deeper part of the photic zone, especially in the BRAZ and SATL provinces, in contrast to most other algae. The Dictyochophyceae were also enriched in the 140-200 m depth layer of the BRAZ and SATL provinces.

In the SPA community four classes of eukaryotic microalgae were identified and displayed a complex biogeographical pattern (Figure 5). Chrysophyceae and Dictyophyceae showed higher abundances in the central provinces (SATL, WTRA, and NAG). Pelagophyceae were depleted, while Dictyochophyceae were more abundant in the deeper part of the photic zone. Remarkably, we detected Braarudosphaera bigelowii (99\% identity with query sequence) a coccolithophore, known for its symbiotic relationship with a cyanobacterium (Thompson et al., 2012). However, we did not find any sequence which was affiliated to the lineage of cyanobacteria UCYN-A.

\section{Numerical Description of Co-occurrence Networks}

From the 15 networks generated we observed that the number of edges and the average number of neighbors were higher in the $\mathrm{FL}$ community and decreased in the SPA and LPA communities, as 


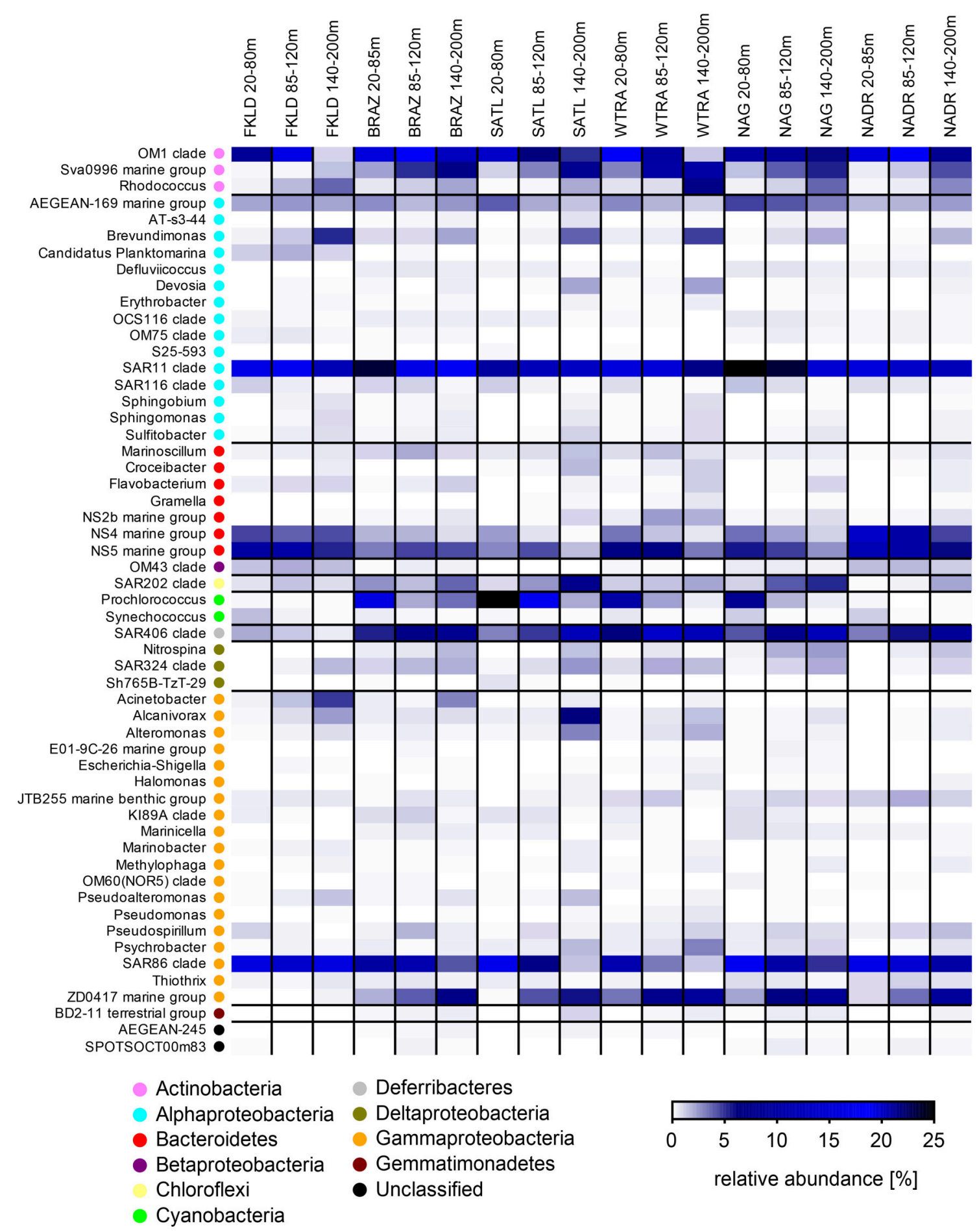

FIGURE 4 | Relative abundance of free-living (FL) marine bacterial clades and genera for the six oceanographic provinces across the whole photic zone: Relative abundance of OTUs classified at the genus and clade level was averaged for the six oceanographic provinces in three depth layers (20-80, 85-120, and 140-200 m). Each line of the heat map represents a taxon, and its higher taxonomic rank (phylum or class) is indicated by the color key.

shown in Figure 6 and reported in Tables S8-S10. For instance we observed that in the $20 \mathrm{~m}$ depth layer the number of edges was 1538 in the FL community and decreased to 965 in the
LPA size fraction despite the comparable number of nodes (134 and 137, respectively for the FL and LPA). These results are reflected in the average number of neighbors per node of the two 

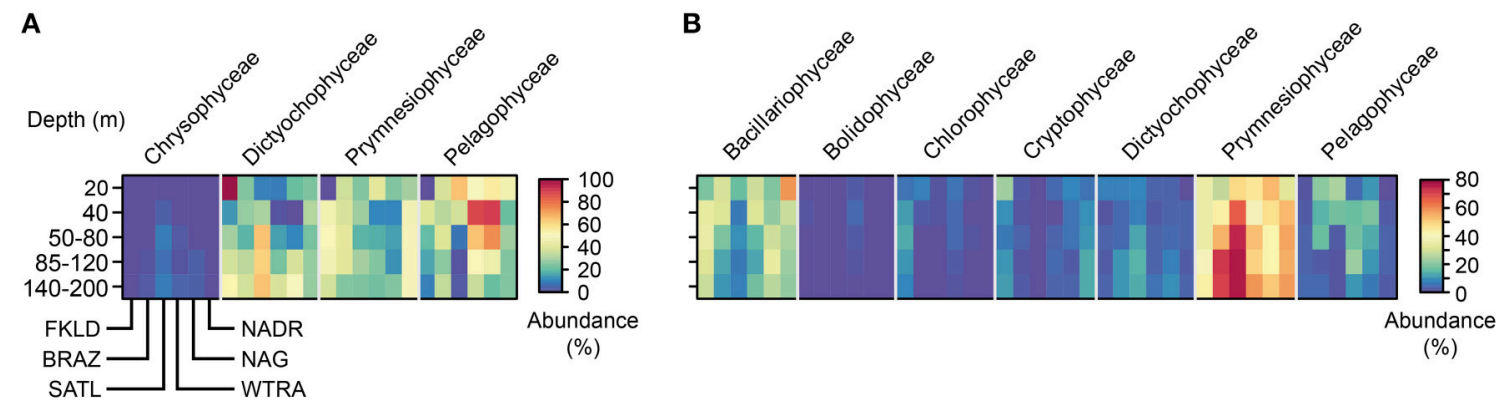

$(\%)$

FIGURE 5 | Taxonomic composition of micro-eukaryote communities across the whole photic zone. Relative abundances for the main taxonomic groups were averaged for the five depth layers in each province. In panel (A) the micro-eukaryotes collected on the $3 \mu \mathrm{m}$ filters (SP) are shown, while in panel (B) the micro-eukaryotes collected on the $8 \mu \mathrm{m}$ filters (LP) are reported. OTUs were grouped at the taxonomic level of class. Each single heat map shows the five depth layers on the $y$-axis from the top to the bottom, and the six oceanographic provinces from South to North on the x-axis. Each taxonomic group is therefore composed of a block consisting of six times five rectangles, encompassing the provinces and depth layers, respectively.

networks (FL and LPA $20 \mathrm{~m}$ depth layer) which were 23 and 14.1 respectively. Overall, those data suggest a higher number of cooccurrences in the FL community. This result was not affected by the number of negative correlations (see below) and in fact when the negative correlations were removed, it was observed that the FL community still had the highest number of neighbors per node throughout the whole water column (Table S11).

Furthermore, we observed that the number of edges of the networks within each size class of the plankton (FL, SPA, and LPA) decreased with depth, reaching the minimum in the 140$200 \mathrm{~m}$ depth layer. In the FL fraction 1538 edges were retrieved in the $20 \mathrm{~m}$ depth layer while only 849 were found in the 140$200 \mathrm{~m}$ depth layer (Figure 6). This shift was even more dramatic in the SPA and LPA fractions, where we found 1437 and 965 edges for the $20 \mathrm{~m}$ depth layer, while only 344 and 243 were retrieved from the 140-200 $\mathrm{m}$ depth layer, respectively. Overall in the last part of the photic zone consistently $50-75 \%$ fewer correlations were found. Analysis of the other topological parameters of the networks (Tables S8-S10) supported those findings and showed a reduction in the complexity of the networks from the upper $(20 \mathrm{~m})$ toward the lower epipelagic zone (140-200 m).

Overall, those results show that particle associated bacteria, although living in close physical contact, tended to establish a much lower number of co-occurrences compared to the free living planktonic bacteria.

\section{Distribution of Negative and Positive Correlations in the Co-occurrence Networks}

We investigated the distribution of the negative and positive correlations along the water column and in different size classes of the plankton (Figure 7). Our analysis revealed that the number of negative co-occurrences was higher in the FL fraction of the plankton (Tables S12-S14). These accounted for roughly $40 \%$ of the total edges and did not follow any bathymetrical pattern. Interestingly, these results were in contrast to the particle associated fraction of the plankton. In both SPA and LPA communities we found that the number of negative associations was higher in the 20 and $40 \mathrm{~m}$ depth layers where they amounted for $40-47 \%$ of the total. However, they were already reduced in the $60 \mathrm{~m}$ depth layer (26-31\%) and reached their minimum in the $140-200 \mathrm{~m}$ depth layer of the LPA fraction where they accounted for $12 \%$ of the total number of co-occurrences (Figure 7).

\section{Taxonomic Structure of Co-occurrence Networks}

We then investigated the taxonomic structure of the networks on the level of OTU (Figure 6). Co-occurrence patterns demonstrated a high degree of association across different phyla and classes, as well as within them, and those association patterns changed across the three size fractions of the plankton and along the water column. In the $20 \mathrm{~m}$ depth layer of the FL network, we found that two clades alone (SAR11 and SAR86) harbored more than $40 \%$ of the total correlations of the network (Figure 8). Moreover, other oligotrophic taxa like AEGEAN-169, OM1, and SAR406 contributed between 6 and 7\% to the total correlation number. In the FL 140-200 depth layer network, we observed a shift in the dominance (in terms of percentage of correlations) of some taxonomic group when compared to the upper layer of the epipelagic zone. The SAR406 clade in fact doubled the amount of total co-occurrences reaching up $15 \%$ of the total. Interestingly, while the SAR86 clade showed a dramatic reduction of the number of association (only 5\% of the total in the $140-200 \mathrm{~m}$ depth layer) the clade SAR11 showed an increased amount of correlations that accounted for $20 \%$ of the total network. Other taxa like the SAR 202, SAR 324, OM1, Sva0996, and the ZD0417 contributed between 3 and $8 \%$ of the total correlations. In the LPA size class of the plankton Bacteroidetes alone had roughly one third (37\%) of the total correlations of the network with Planctomycetes and Verrucomicrobia contributing to 4 and 3\% of the network cooccurrences and Gammaproteobacteria accounting for about $10 \%$. In the LPA $140-200 \mathrm{~m}$ network, the amount of cooccurrences attributed to Bacteroidetes decreased to $22 \%$, while those derived from the Gammaproteobacteria increased to $23 \%$ of the network. Alphaproteobacteria were found to have roughly $15 \%$ of the total correlations of the network, with Planctomycetes, 

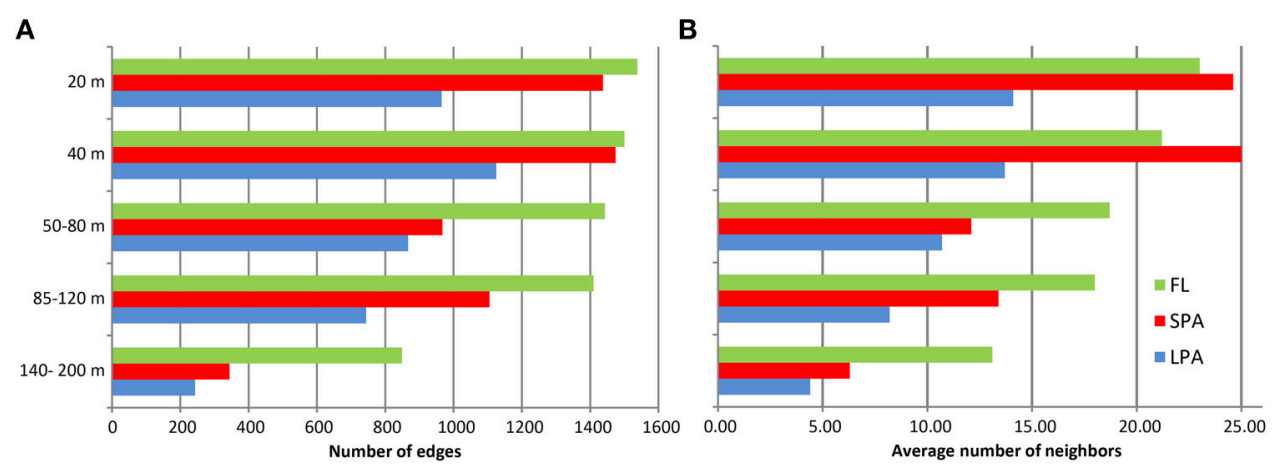

C

FL
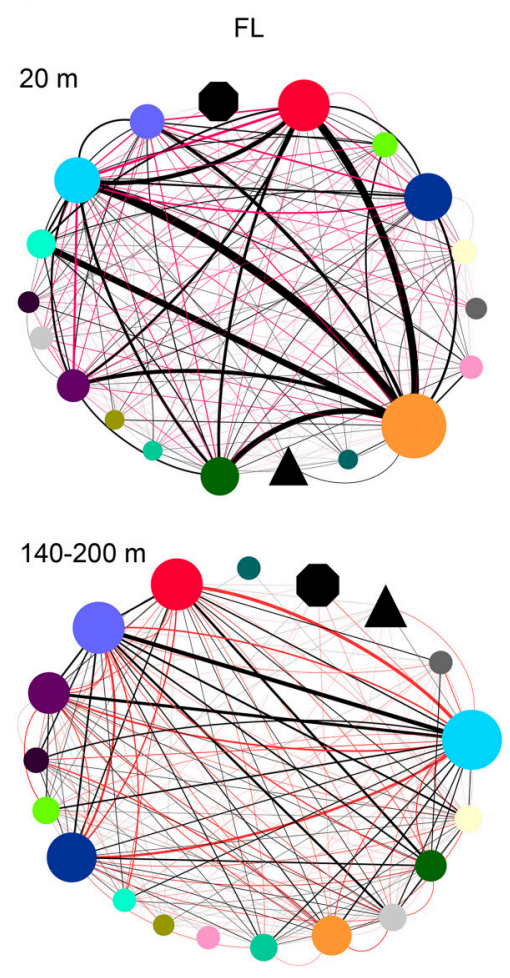

1 Node Size
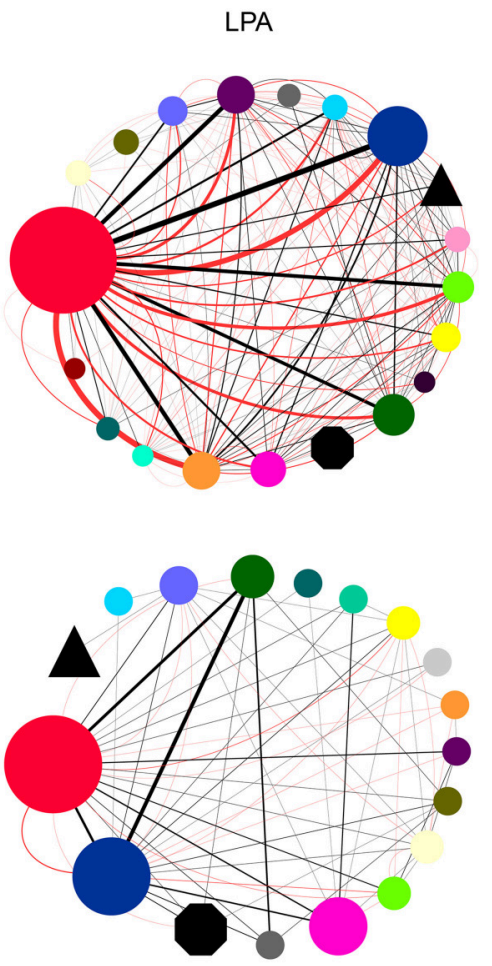

LPA

Taxa

AEGEAN-169 marine group

Actinobacteria

Alphaproteobacteria

Bacteroidetes

Betaproteobacteria

Cyanobacteria

Deltaproteobacteria

Gammaproteobacteria

Lentisphaerae

OM1 clade

Planctomycetes

SAR11 clade

SAR116 clade

SAR324 clade(Marine group B)

SAR406 clade(Marine group A)

SAR86 clade

Sva0996 marine group

Verrucomicrobia

ZD0417 marine group

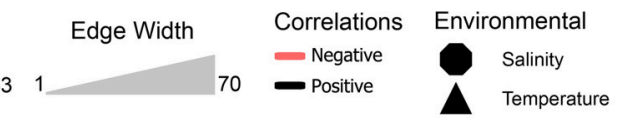

FIGURE 6 | Bacterioplankton co-occurrence networks. Network analysis was performed at the OTU level for each depth layer and size fraction of the plankton. Selected topological parameters of the networks are plotted: (A) Number of edges in each network and (B) average number of neighbors per node. See

Tables S8-S10 for the full set of network parameters. (C) The four most extreme networks are displayed: The 20 and 140-200 m depth layer (top to down) of the FL and LPA communities (left to right), respectively. In order to better display co-occurrence patterns OTUs were grouped at different taxonomic level (known marine clades as well as classes and phyla). The size of each oval (node) indicates the number of OTUs belonging to that taxonomic group, while the size of environmental parameters (temperature and salinity) was arbitrary defined. Lines connecting two nodes represent a group of strong $(R>0.6)$ and significant correlations $(p<0.05)$. Black lines indicate a positive correlation while red lines indicate a negative correlation. The width of each line exhibit the number of correlations occurring among the two connected nodes.

Verrucomicrobia, SAR324, SAR406, SAR 202, and Sva0996 contributing between 2 and $5 \%$ of the total co-occurrences. Overall it emerges that the co-occurrence patterns strongly changed along the water column and between different size fractions of the plankton. The FL networks were dominated by oligotrophic clades like the SAR11, SAR86, and SAR406. Those were only marginally retrieved in the LPA size class and probably reflect trophic relationship within planktonic communities i.e., protist collected on the $8 \mu \mathrm{m}$ membrane were feeding on the most dominant free-living bacteria (Hartmann et al., 2012, 2013). The LPA community was instead dominated by groups of microorganisms like Bacteroidetes, Gammaproteobacteria as well as the Alphaproteobacteria not affiliated to known streamlined marine lineages (Swan et al., 2013). 


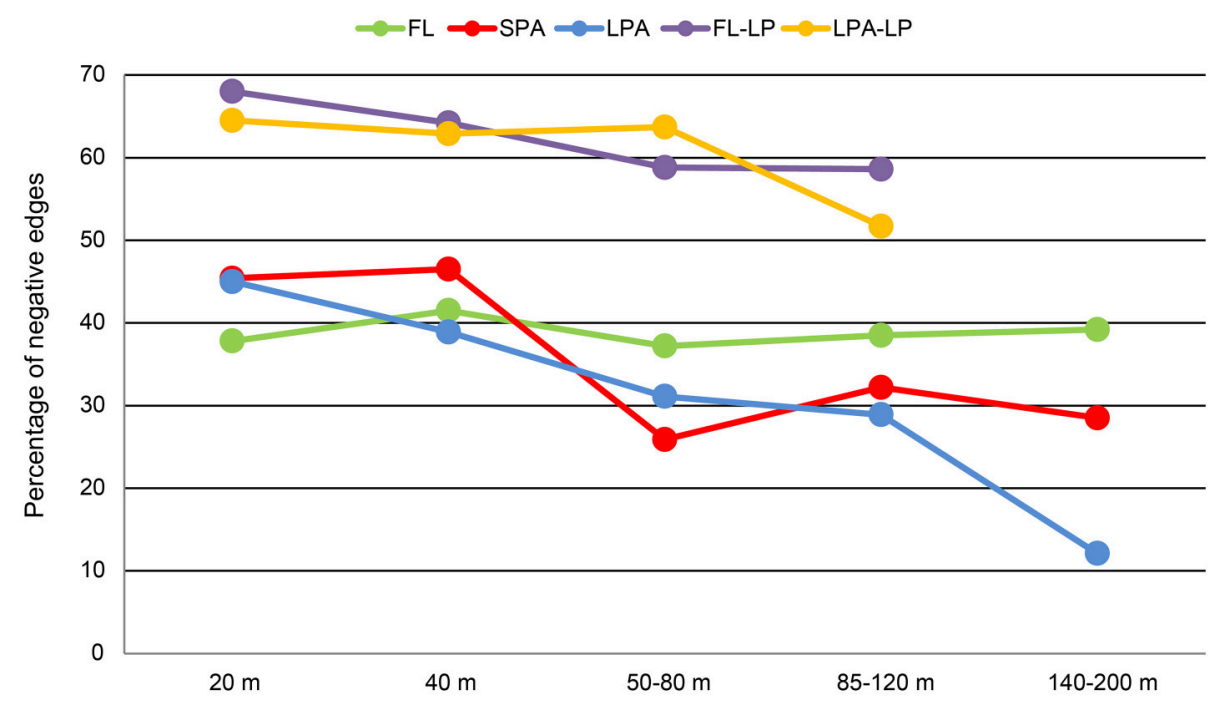

FIGURE 7 | Bathymetric distribution of negative correlations. For each of the networks generated (15 bacteria-bacteria networks and 8 bacteria-micro-eukaryotes networks) the relative amount of negative correlations is plotted against depth. Different colors distinguish the networks: FL, free-living bacteria; SPA, small particle associated bacteria; LPA, large particle associated bacteria; FL-LP, free-living bacteria and micro-eukaryotes retrieved from the $8 \mu \mathrm{m}$ membranes; and LPA-LP, large particle associated bacteria and micro-eukaryotes retrieved from the $8 \mu \mathrm{m}$ membranes.

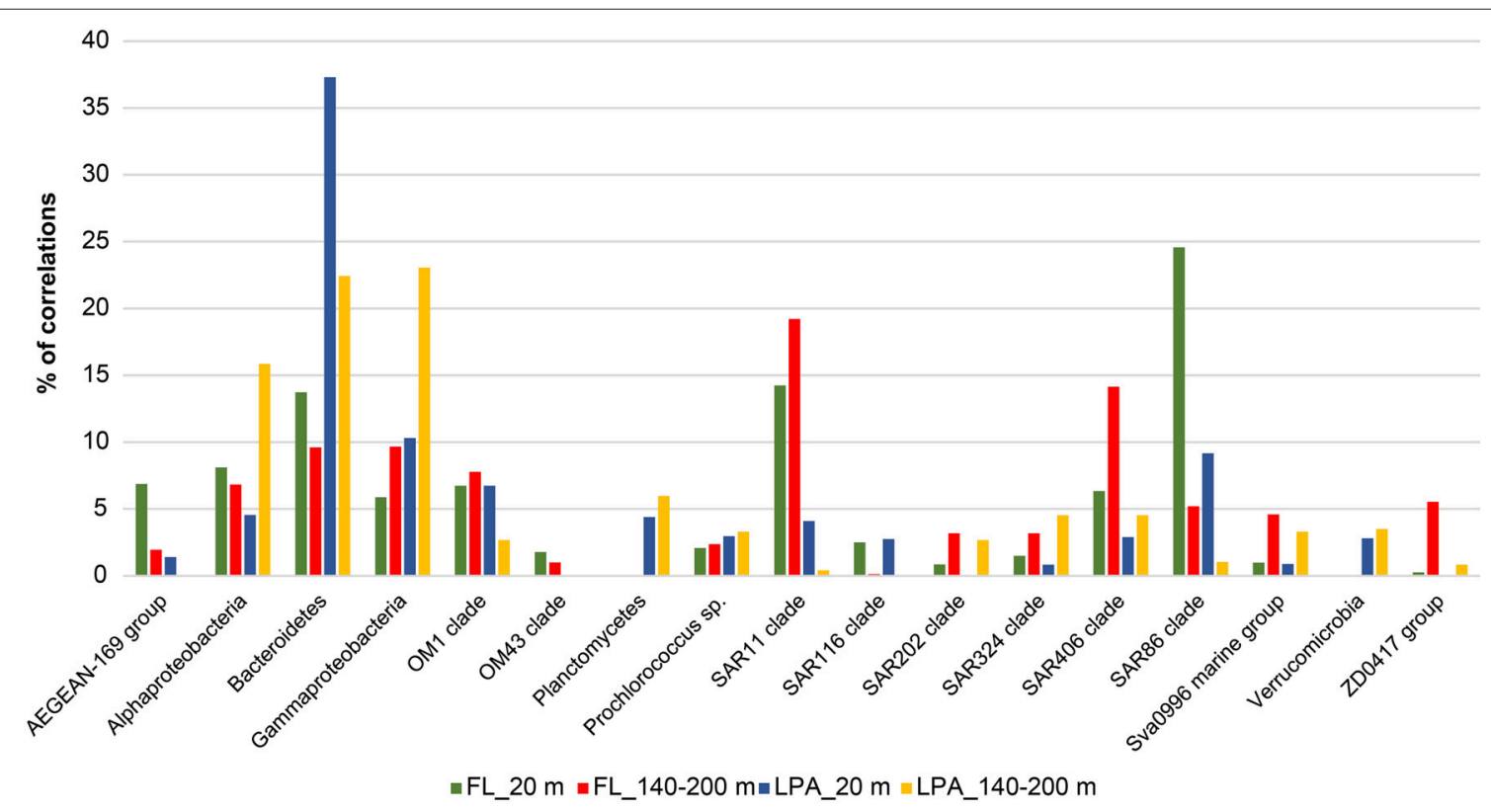

FIGURE 8 | Relative contribution to the total number of correlations for different taxonomic groups for the depth stratified networks: Network analysis was performed at the OTU level for each depth layer and size fraction of the plankton as described in Materials and Methods. Nodes belonging to the same taxonomic group (known important marine clades as well as classes and phyla of the bacterioplankton) were grouped together and the relative amount of correlations was calculated and expressed as percentage of the total number of correlations of the network. Four networks are here displayed (FL_20, FL_140-200, LPA_20, and LPA140_200 m) with different colors.

\section{Associations between Eukaryotic Microalgae and Bacteria}

To investigate algae-bacteria co-occurrences, correlations were calculated between bacterial present OTUs in the FL and LPA communities with the micro-eukaryotes found on the $8 \mu \mathrm{m}$ membranes. Analysis of the topological coefficients of the two networks (FL bacteria with micro-eukaryotes and LPA bacteria with micro-eukaryotes) revealed a reduction of the number of nodes and edges from the $20 \mathrm{~m}$ depth layer toward the $85-120 \mathrm{~m}$. Moreover, the average number of neighbors decreased with depth while the characteristic path length increased (Tables S15, S16). Overall those analyses suggest 
a bathymetric stratification of the networks similar to what reported for the bacterial networks. In the FL community Alphaproteobacteria and Gammaproteobacteria, which includes the highly abundant SAR11 and SAR86 clades, dominated the network (Figure 9). Most of the correlations occurred with members of the Prymnesiophyceae and Dictyophyta. In the LPA community the co-occurrence networks were more complex showing additional associations with Bacteroidetes, Verrucomicrobia, and Planctomycetes. Furthermore, we found that most of the edges $(\sim 60 \%)$ analyzed here were negative (Figure 7). These were higher in the upper layers $(20 \mathrm{~m})$, where amounted for $65-68 \%$ of the total, and slightly decreased toward the 85-120 m depth layer (54-58\%) (Table S17 and Figure 7).

From our analysis it emerged that the association patterns between phytoplankton and bacteria were not strictly taxonomically constrained, i.e., the same bacterium was not found to be always associated with the same algal OTUs. This, in our opinion, suggests that the associations between phytoplankton and bacteria are rather opportunistic and might follow stochastic processes.

Most of the associations were negative which might indicate top-down processes and antagonistic relationships.

\section{DISCUSSION}

\section{Taxonomic Composition of Bacterioplankton Communities}

Here we characterized bacterial communities of a transect across the Atlantic Ocean with Illumina sequencing of the V5-V6 region of the 16S rRNA gene. Overall, our taxonomic investigation was in accordance with previous studies with respect to the relative abundances of many known marine groups (Rusch et al., 2007; Schattenhofer et al., 2009; Friedline et al., 2012; Morris R. M. et al., 2012; Sunagawa et al., 2015). Actinobacteria were found to be more abundant when compared to other studies (Rusch et al., 2007; Morris R. M. et al., 2012; Sunagawa et al., 2015). This finding was related to the high relative abundance of the recently characterized Actinominuta temperata (OM1 clade) (Ghai et al., 2013). This clade of the marine bacterioplankton was described as having one of the smallest cell sizes described so far in the ocean, with an estimated genome size $<1 \mathrm{Mb}$ (Ghai et al., 2013), and hence represents a typical oligotrophic organism with a streamlined genome (Giovannoni et al., 2014). The clade was found to be extremely abundant throughout the whole transect ( $20 \%)$ highlighting its importance in the marine ecosystem together with the other abundant and widespread oligotrophic bacterial lineages like SAR11, SAR86, and Prochlorococcus sp. (Morris et al., 2002; Rusch et al., 2007; Dupont et al., 2012; Sunagawa et al., 2015).

The biogeography of most of the taxa identified here was related to three main parameters: province, depth layer, and filter size and will be discussed below.

\section{Province}

Six biogeochemical provinces according to Longhurst were covered (Longhurst, 1998). The concept of biogeochemical provinces was developed to predict algal blooms in the ocean.
It is based on the dynamics of surface temperature, salinity, bathymetry and chlorophyll $a$ concentration and has been refined ever since (Reygondeau et al., 2013). Thus, these provinces provide an ecologically tremendously useful framework for interpreting biogeographical data. The different provinces of the transect had different community composition, with enrichment and depletion of specific taxa, like the clade SAR11 which was more abundant in the FL community of the BRAZ and NAG provinces. Other examples of taxa with a province related distribution (provincialism) were observed, among those a remarkable example was Bacteroidetes. This group of bacteria is known to be associated to phytoplankton (Gómez-Pereira et al., 2012; Buchan et al., 2014); they are able to metabolize polysaccharides produced by the phytoplankton and dominate the community during algal blooms (Teeling et al., 2012; Wemheuer et al., 2014). Here we show that they comprised one of the most important phyla in the two marginal provinces of the transect: FKLD and NADR, which are highly productive areas of the Atlantic Ocean (Chust et al., 2013; De Monte et al., 2013).

\section{Depth}

We observed a shift in community composition along the water column, which mainly involved members of the Alphaproteobacteria and Gammaproteobacteria as well as the clades SAR202 and SAR406. The deeper layers of the photic zone might represent a transition environment between the deep ocean $(>200 \mathrm{~m})$ and the euphotic zone. Members of the SAR202 and SAR406 are extremely important in the mesopelagic and bathypelagic zones of all oceans (Salazar et al., 2015), and seem like many other Gammaproteobacteria to be adapted to light reduced environments. Those taxa were the most abundant across the complete transect in the 140-200 m depth layer. The pattern was conserved for all three filter sizes, indicating that the deeper layers of the photic zone (140-200 m) represent a unique environment. Despite the extensive sampling area that covered almost the entire Atlantic Ocean, those communities were remarkably similar. These findings corroborate the hypothesis (Aristegui et al., 2009) that systems not driven by light, e.g., the dark ocean, are more homogeneous than the photic zone with respect to their community composition and with respect to diversity patterns.

\section{Filter Size}

Our taxonomic analysis showed that the three filters harbored different communities, with enrichment of Planctomycetes, Verrucomicrobia, Deltaproteobacteria, and Bactereoidetes on the particles and depletion of taxa like SAR11 and SAR86, in agreement with previous studies carried out in the Atlantic Ocean and other regions (DeLong et al., 1993; Crump et al., 1999; Ganesh et al., 2014; Mohit et al., 2014; Bižic-Ionescu et al., 2015; Fontanez et al., 2015; Salazar et al., 2015). However, these results concern only higher taxonomic ranks like phylum and class. When investigated at the clade and genus level, we observed that the three size fractions of the plankton analyzed here harbored different taxa for almost each of the phyla and classes identified. These data show that the particle associated lifestyle is a widespread feature of marine bacteria, and present 


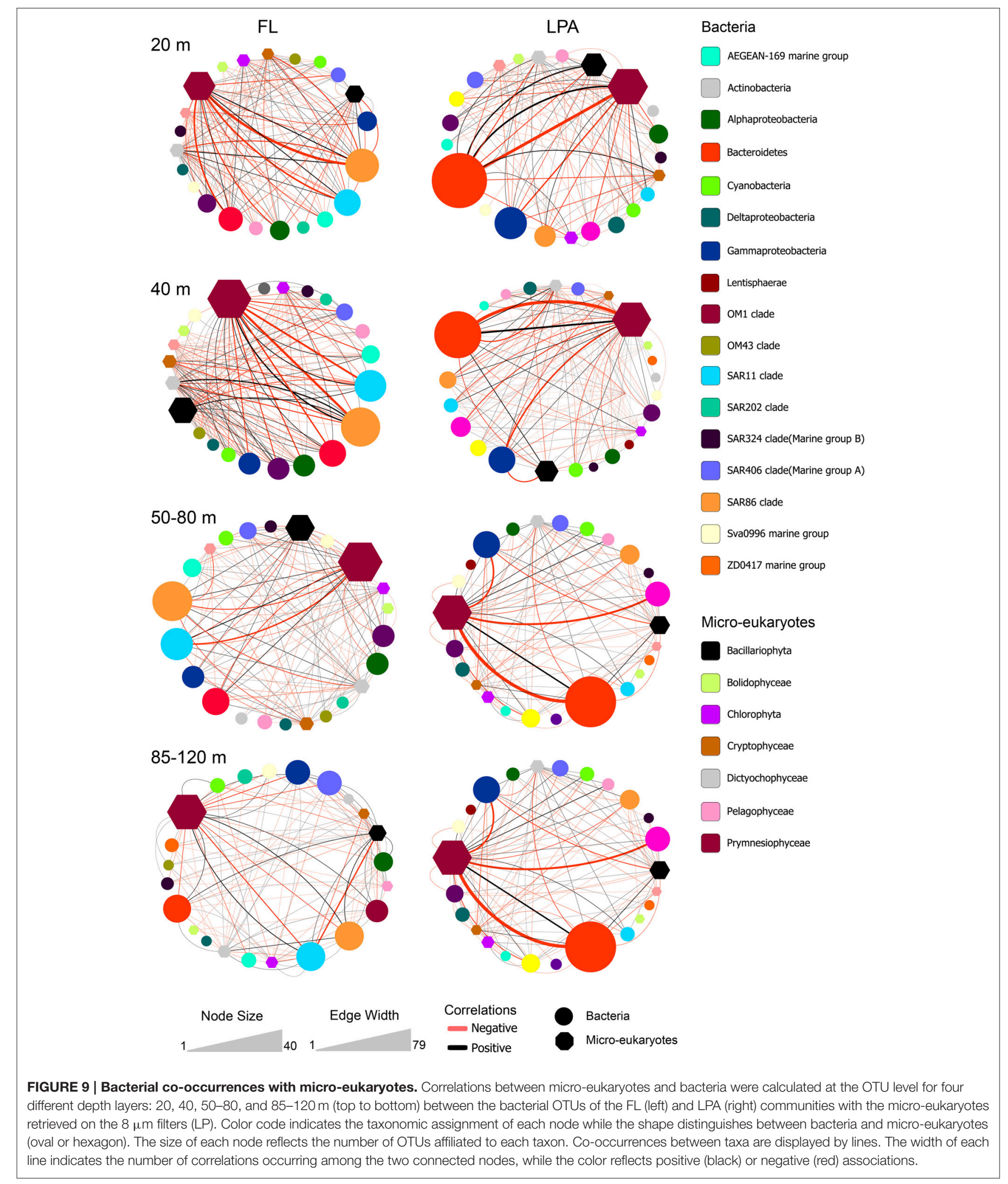

among all phyla and classes of the bacterioplankton. However, some phyla like Planctomycetes and Verrucomicrobia seem to have evolved only a particle associated lifestyle, while in groups like the Alphaproteobacteria and Gammaproteobacteria both lifestyles are present. Those findings suggest, as recently reported for the deep ocean (Salazar et al., 2015), that the particle 
associated lifestyle is a conserved trait of the bacterioplankton also in the photic zone, and that more emphasis should be put in studying microbial communities associated to particles. However, it must be taken into account that those results are likely to be influenced by filtration biases (Padilla et al., 2015) as well as top-down processes like predation, i.e., free-living bacteria that were ingested by eukaryotes were retained on the bigger size fraction of the plankton. Those issues are hard to solve and in fact the free-living bacteria like SAR11, SAR86, and Prochlorococcus sp. have been found to be highly abundant on particles in previous studies (Crespo et al., 2013; Bižic-Ionescu et al., 2015; Rieck et al., 2015).

Bacterioplankton community composition is strongly influenced by seasonal processes (Gilbert et al., 2012; Bryant et al., 2015; Fuhrman et al., 2015). In our study, the sampling time was roughly 5 weeks and, therefore, our data do not address seasonality and are influenced by the time of the year sampled (April-May).

\section{Comparison of Our Networks with Previously Published Planktonic Networks}

Previous analyses have investigated the network composition and structure of planktonic communities with particular emphasis on time series data. It is therefore worthwhile to compare the complexity of previous networks in terms of number of nodes and edges. In a recent depth stratified analysis of bacterioplankton communities (Cram et al., 2015b), it was shown that the total number of nodes per layer was between $57(890 \mathrm{~m}$ depth) and 83 (150 m depth) and in total 537 nodes with 2301 edges were found. A time series study at the SPOT station revealed that the bacteria-bacteria network was constituted by 226 nodes and 837 edges (Chow et al., 2013). Peura and colleagues reported a total of 308 nodes and 1436 edges for the HOT station (Peura et al., 2015). In the Tara Oceans study several networks were constructed for the different size classes of the plankton as well as for the two depth layers (Lima-Mendez et al., 2015). For the bacterioplankton networks from the FL fraction, a total of 716 and 795 nodes were found for the surface samples $(5 \mathrm{~m}$ ) and the DCM (deep chlorophyll maximum), with respectively 1749 and 2838 edges. Thus, differences in the methods of network construction as well as sequencing method strongly affect the network structure and complexity (Faust and Raes, 2012; Faust et al., 2015a,b). However, from those data it emerges that in our study a higher number of correlations per node was retrieved in the FL community, also if compared to the Tara oceans study. This might reflect the narrower geographical range studied here and the different sequencing method used.

\section{Network Analysis Shows Highly Interconnected Networks for Free-Living Bacterioplankton}

Analysis of the topological parameters of the three networks (FL, SPA, and LPA) revealed a higher number of correlations in the FL community while the particle fractions showed a reduced number of correlations. Those findings are to a certain extent illogical: why are particle associated bacteria establishing fewer co-occurrences than the free-living ones, in spite of their close physical neighborhood? According to the "lottery hypothesis" particles might be colonized by chance with a few phylotypes out of the huge diversity of bacteria with similar functional traits, as suggested for the Ulva australis holobiont (Sale, 1979; Burke et al., 2011a,b). Metagenomic studies reported that particle associated bacteria have on average a larger genome (Zeigler et al., 2012; Allen et al., 2013), with enrichment of genomic traits that mediate interactions, vitamins synthesis, and polysaccharide degradation (Smith et al., 2013; Ganesh et al., 2014; Satinsky et al., 2014; Simon et al., 2014) as well as genes related to competition (Ganesh et al., 2014), supporting the idea that lineages enriched on particles have a copiotrophic lifestyle rather than an oligotrophic one (Allen et al., 2013). The higher number of genes might represent an advantage in a nutrient rich environment (Giovannoni et al., 2014) allowing them to adapt quickly to available nutrients without the need to establish interactions with neighboring microorganisms. On the other hand, free-living bacteria often have a streamlined genome (Swan et al., 2013), which has been proposed as a competitive advantage in nutrient poor environments (Giovannoni et al., 2014). Many members of the bacterioplankton lack metabolic pathways for the synthesis of essential nutrients like vitamins (Giovannoni, 2012; SañudoWilhelmy et al., 2014).

The most abundant bacterioplankton taxa, like SAR11, SAR86 and Prochlorococcus sp. have streamlined genomes nevertheless, they dominate bacterioplankton communities on a planetary scale (Rusch et al., 2007; Sunagawa et al., 2015). In this study, we observed that the candidatus $A$. minuta (OM1 clade), which has been described as the smallest marine bacterium, with a genome that might be smaller than $1 \mathrm{Mb}$ (Ghai et al., 2013), is also extremely abundant. The authors proposed a photoheterotrophic lifestyle and further suggested association with cyanobacteria (Ghai et al., 2013). Here we showed that the clade was also abundant in regions were cyanobacteria were almost undetectable (FKLD) suggesting that its relative abundance does not depend upon the presence of cyanobacteria.

How can those microorganisms be so successful despite the absence of essential genes? Morris and colleagues postulated the "black queen hypothesis" (BQH) (Morris J. J. et al., 2012) stating that members of the microbial community can be classified as "helpers" and "beneficiaries." Beneficiaries are abundant genome streamlined organisms that rely on helpers for essential metabolites or other "services" that allow their survival and ecological success; in turn, they provide the helpers with metabolites. Based on a systematic analysis of possible metabolic interactions in 800 different microbial communities from a wide range of environments (soil, aquatic, marine, and human gut) Zelezniak et al. (2015) concluded that microbial communities harbor highly interconnected groups of taxa that exchange metabolites like sugars and amino acids and co-occur in different habitats. The interdependencies among different 
microorganisms would thereby explain the inability of culturing marine bacteria. A recent paper which used a mixed culture approach (Garcia et al., 2015) based on metagenomics data suggested that Crenarcheota provided the cofactor B12 to the bacterial members of the community. Interestingly, a time series analysis of the SPOT station, during a time frame of roughly 3 years has shown that members of the SAR86, as well as of the SAR11 clades strongly co-occurred with Crenarcheota suggesting a possible interdependency since both clades (SAR11 and SAR86) are auxotrophic for cobalamin (Beman et al., 2011). A recent network analysis of freshwater and marine bacterioplankton accordingly found that the abundant taxa, which typically have streamlined genomes, tend to have a higher number of cooccurrences (Peura et al., 2015). A time series analysis of metatranscriptome data from two different marine environments established functional community networks which showed high inter-taxa correlations and coordination of several metabolic pathways which was taxonomy independent but rather time related indicating the existence of complex patterns of metabolic interdependency which are not only spatially constrained but also time dependent (Aylward et al., 2015). Genes related to amino acid metabolism, DNA processing, translation, transporters, and vitamin metabolism had the highest connectivity of all transcripts which suggests a tight regulation of those features within the community (Aylward et al., 2015). Taking all findings together, the higher abundance of bacteria with streamlined genomes (SAR11, SAR 86, OM1, and Prochlorococcus sp.) in the FL community might explain the larger number of correlations observed. Those bacteria are critically dependent on metabolites which might be provided by the surrounding members of the planktonic communities, suggesting that the $\mathrm{BQH}$ could be one of the mechanisms contributing to network topology in the FL fraction. Species living on the particles instead have large genomes that might allow them to be more independent.

\section{Depth Stratified Co-occurrences Networks}

We observed that the number of co-occurrences between bacterial OTUs decreased with depth and was lowest in the $140-200 \mathrm{~m}$ depth layer for all size fraction of the plankton, which, to the best of our knowledge, has not been observed before (Chow et al., 2013; Cram et al., 2015a,b). By contrast, in the Tara oceans study (Lima-Mendez et al., 2015) it was shown that bacterioplankton communities collected on 0.22 $\mu \mathrm{m}$ membranes had a much higher number of correlations in the DCM compared to surface samples $(5 \mathrm{~m})$. Overall, those studies suggest that the stratification of planktonic communities does not only involve a shift in the taxonomic composition (Eiler et al., 2011; Vergin et al., 2013; Sunagawa et al., 2015) and in the diversity (Bryant et al., 2015; Cram et al., 2015a; Sunagawa et al., 2015; Milici et al., 2016b) but also in the network structure and co-occurrence patterns. The link and intersection between planktonic networks from different depth layers can help us to understand the global carbon cycle (Guidi et al., 2016).

\section{Negative Correlations Are an Important Driver of the Free-Living Fraction of the Plankton}

In our analysis, we found that roughly one third of the correlations retrieved in the FL community of the bacteriopalnkton were negative. This result indicates that mutual exclusion plays an important role in shaping community composition and could be caused by antagonistic associations or reflect niche partitioning (Chaffron et al., 2010; Hibbing et al., 2010; Freilich et al., 2011). Studies on time series data have reported a comparable amount of negative correlations, e.g., Chow and colleagues reported that negative associations accounted for $\sim 30 \%$ at SPOT (Chow et al., 2014) and comparable results were found for lake bacterioplankton (Eiler et al., 2012). Co-occurrence analyses over large geographical distance have also reported a similar amount of negative correlations ( 25\%) (Lima-Mendez et al., 2015) although most of them occurred between eukaryotes and between bacteria and eukaryotes, suggesting almost no antagonistic processes among bacterioplankton. However, when only prokaryotic communities were analyzed, it emerged that negative co-occurrences amounted for roughly $11.5 \%$ of the surface $(5 \mathrm{~m})$ network and only $1.5 \%$ of the DCM network. Those values are significantly smaller than ours $(\sim 35 \%)$. It must be taken into account that in our study the sampling time was much shorter (5 weeks) compared to the 4 years of the Tara Oceans expedition. Cooccurrences are known to follow seasonal patterns (Fuhrman et al., 2015). Moreover, the 300 samples from the Tara Oceans study were derived from all oceans and all size fractions of the plankton (from viruses to mesoplankton), thus the study is based on a geographically much more heterogeneous sample set. Yet in spite of discrepancies in the relative abundance of negative correlations, it clearly emerges that they are commonly retrieved in the FL fraction of the bacterioplankton.

We also show that the number of negative correlations decreased in the particle associated fraction of the bacterioplankton (SPA and LPA) and in particular in the 140-200 m depth layer of the LPA community. Those findings might suggest that particle-associated bacteria, although living in physical proximity, are less likely to establish mutual exclusion processes, especially toward the end of the epipelagic zone. Bacteria that live on particles are known to harbor genomic features devoted to competition, e.g., type VI secretion systems and antibiotics (Dang and Lowell, 2016). Our data suggest that those traits might not necessarily be expressed under carbon limiting conditions in the deeper layers of the photic zone (Giering et al., 2014). However, it must be taken into account that our analysis was based on $16 \mathrm{~S}$ amplicon sequencing of the rRNA gene and therefore do not provide any information on the activity of bacterial cells collected on the filters.

\section{Distribution of Micro-Eukaryotes and Their Co-occurrences with Bacterioplankton}

Bacterioplankton widely interact with phytoplankton (Amin et al., 2012, 2015; Lima-Mendez et al., 2015), and provide 
it with several compounds, like reduced forms of sulfur like DMSP (Tripp et al., 2008; Moran et al., 2012), polysaccharides (Teeling et al., 2012; Buchan et al., 2014), vitamins (WagnerDöbler et al., 2010; Amin et al., 2012) and growth hormones (Amin et al., 2015). From the small (SPA) and large (LPA) particles we retrieved different groups of eukaryotic microalgae based on the plastidial 16S rRNA gene. Eukaryotic 16S rRNA sequences that are amplified with universal bacterial primers are usually discarded in most environmental studies, but they actually provide taxonomically useful information. We show that sequences retrieved with the bacterial primers F807 and R1050 (Bohorquez et al., 2012) cover almost 70\% of the marine eukaryotic photosynthetic lineages of the PhytoREF database (Decelle et al., 2015) offering the opportunity to investigate the distribution of eukaryotic microalgae. However, interpretation must take into account the primer coverage and the issue of $16 \mathrm{~S}$ rRNA gene copy number, which varies across taxonomic groups. In our study, the two most abundant classes of eukaryotic microalgae identified were Prymnesiophyceae (haptophytes) and Bacillariophyceae (diatoms). These results are similar to previous studies that used other molecular tools (Kirkham et al., 2011, 2013; de Vargas et al., 2015) or measurement of accessory pigments via HPLC (Barlow et al., 2002). The distribution of these two classes of eukaryotic microalgae observed here is consistent with worldwide modeling based on accessory pigments (Liu et al., 2009). Thus, our analysis was able to detect accurately the main players of the photosynthetic microeukaryotic community.

Co-occurrence analysis among bacteria and phytoplankton showed no clear taxonomic pattern. Several bacterial taxa coexisted with different micro-eukaryotes. This finding sustains the competitive "lottery hypothesis" (Sale, 1979), according to which species that belong to the same ecological guild, and hence, have the same ecological function, colonize spatial niches by chance. Several studies have shown the absence of species-specific associations among bacteria and macro-algae (Campbell et al., 2015; Marzinelli et al., 2015; Dittami et al., 2016), confirming the lottery hypothesis. Furthermore, we observed that most of the correlations between bacteria and micro-eukaryotes were negative $(\sim 60 \%)$. Those findings indicate mutual exclusion between the two communities of the plankton. A previous study investigating planktonic community at the SPOT station (Chow et al., 2014) has shown that top-down processes accounted for roughly $30 \%$ of the total correlations. Many micro-eukaryotic algae can be mixotrophic and feed on bacteria (Hartmann et al., 2012, 2013). Studies on members of the roseobacter clade have shown that the relationship between micro-eukaryotes and bacteria can switch from a mutualistic toward a pathogenic stage during co-culture (Seyedsayamdost et al., 2011; Wang et al., 2014).

\section{CONCLUSION}

Deep sequencing of the bacterioplankton revealed province, depth and filter size specific communities with little overlap in the epipelagic zone of the Atlantic Ocean. Network analysis indicated that there are more correlations in the free-living bacteria than in the communities associated to particles. Cooccurrence patterns were shown to be bathymetrically stratified with a reduction of associations in the deepest layer of the photic zone. Negative correlations were especially high in the upper layers of the photic zone and decreased with depth and particle size. Eukaryotic microalgae-bacteria network analysis showed that there was no specific taxonomic association between bacterial taxa and micro-eukaryotic algae. Understanding how bacteria interact across space and time with other parts of the biota is essential in order to predict the adaptation and evolution of the ocean microbiome in the framework of climate change.

\section{AUTHOR CONTRIBUTIONS}

MM isolated the DNA, IP, DP, MW provided the method for sequencing and constructed the amplicon libraries and RJ performed bioinformatics analysis. MM, JT, and ZD analyzed the data. TB analyzed the oceanographic data, JD contributed to the data analysis. HG, MW, and MS measured environmental parameters. IW and HW collected the samples during the oceanographic cruise. MS organized the oceanographic cruise. IW supported and supervised the research. MM and IW wrote the manuscript, all authors reviewed the manuscript.

\section{ACKNOWLEDGMENTS}

We thank the crew of RV Polarstern for their excellent support during samples collection. This work was funded by Deutsche Forschungsgemeinschaft (DFG) in Transregio-SFB TR51. JD was supported by the OCEANOMICS project, funded by the French Government and managed by the Agence Nationale de la Recherche, under the grant agreement "Investissements d'Avenir" ANR-11-BTBR-0008.

\section{SUPPLEMENTARY MATERIAL}

The Supplementary Material for this article can be found online at: http://journal.frontiersin.org/article/10.3389/fmicb. 2016.00649

Table S1 | Environmental metadata and geographical positions. Geographical location of sampling stations, environmental parameters, and factors used for multivariate statistics (province, depth layer) are reported.

Table S2 | Taxonomic placement of ambiguous reads. Sequences that could not be assigned at the domain and phylum level were manually reassigned, when possible, via phylogenetic analysis. Results from the original taxonomic classification and the reassignment can be found in the sheet "SINA and curated classification," while the BLAST results against the SILVA database 119 NR are reported in "BLAST ambiguous sequences."

Table S3 | Sequencing results and taxonomic affiliation of OTUs. Numbers of raw reads and bacterial sequences are listed, together with information about the relative abundance of each OTU within the three bacterial communities FL, SPA, and LPA and the eukaryotic microalgae SP and LP. For each OTU abundance data, sequence, and taxonomic information according to the SILVA 119 NR database are reported. 
Table S4 | Networks data for the three size fractions of the plankton along the water column. For each of the 15 networks calculated as described in Materials and Methods the original data are reported. Only statistical significant $(p<0.05)$ and strong correlations $R>0.6$ are listed.

Table S5 | Number of indirect correlations with environmental parameters removed.

Table S6 | Percentage of OTUs classified at different taxonomic levels.

Table S7 | Coverage of primers F805 and R1050 of the marine photosynthetic lineages. Chloroplast $16 \mathrm{~S}$ of all the marine photosynthetic eukaryotes were extracted from the PhytoREF database and in silico investigated for the coverage of the primers.

Table S8 | Topological coefficients of the depth stratified networks for the FL community.

Table S9 | Topological coefficients of the of the depth stratified networks for the SPA community.

Table S10 | Topological coefficients of the of the depth stratified networks for the LPA community.

Table S11 | Number of average neighbors for all size fractions of the plankton (FL, SPA, and LPA) without negative correlations.

Table S12 | Percentage of positive and negative correlations among OTUs and among OTUs and environmental parameter for the depth stratified FL networks.

Table S13 | Percentage of positive and negative interactions among OTUs and among OTUs and environmental parameter for the depth stratified SPA networks.

Table S14 | Percentage of positive and negative interactions among OTUs and among OTUs and environmental parameter for the depth stratified LPA networks.
Table S15 | Topological coefficients for the depth stratified co-occurrence networks between FL bacteria and micro-eukaryotes collected on the 8 $\mu \mathrm{m}$ membranes.

Table S16 | Topological coefficients for the depth stratified co-occurrence networks between LPA bacteria and micro-eukaryotes collected on the 8 $\mu \mathrm{m}$ membranes.

Table S17 | Percentage of positive and negative correlations between FL bacteria and LP micro-eukaryotes and LPA bacteria with LP micro-eukaryotes.

Figure S1 | Phylogenetic analysis of ambiguously assigned sequences. Sequences that could not be taxonomically assigned further than domain level were manually inspected. Reference sequences were downloaded from SILVA NR 119 and the neighbor-joining method was used for tree construction.

Figure S2 | Cumulative dominance plots: After pre-treatment of the OTUs abundances as reported in materials and methods, a dominance plot was calculated for each of the three size fractions of the plankton: FL, SPA, and LPA. The first 10 most abundant OTUs are reported for each plot (x-axis) and their relative cumulative contribution ( $y$-axis).

Figure S3 | Relative abundance of small particle associated (SPA) marine bacterial clades and genera for the six oceanographic provinces across the whole photic zone: Relative abundance of OTUs classified at the genus and clade level was averaged for the six oceanographic provinces in three depth layers. Each line of the heat map represents a taxon, and its higher taxonomic rank (phylum or class) is indicated by the color key.

Figure S4 | Relative abundance of large particle associated (LPA) marine bacterial clades and genera for the six oceanographic provinces across the whole photic zone: Relative abundance of OTUs classified at the genus and clade level was averaged for the six oceanographic provinces in three depth layers. Each line of the heat map represents a taxon, and its higher taxonomic rank (phylum or class) is indicated by the color key.

chlorophyll maximum of coastal California. ISME J. 5, 1077-1085. doi: 10.1038/ismej.2010.204

Berry, D., and Widder, S. (2014). Deciphering microbial interactions and detecting keystone species with co-occurrence networks. Front. Microbiol. 5:219. doi: $10.3389 /$ fmicb.2014.00219

Bižic-Ionescu, M., Zeder, M., Ionescu, D., Orlic, S., Fuchs, B. M., Grossart, H. P., et al. (2015). Comparison of bacterial communities on limnic versus coastal marine particles reveals profound differences in colonization. Environ. Microbiol. 17, 3500-3514. doi: 10.1111/1462-2920.12466

Bohorquez, L. C., Delgado-Serrano, L., López, G., Osorio-Forero, C., KlepacCeraj, V., Kolter, R., et al. (2012). In-depth characterization via complementing culture-independent approaches of the microbial community in an acidic hot spring of the Colombian Andes. Microb. Ecol. 63, 103-115. doi: 10.1007/s00248-011-9943-3

Brown, C. T., Hug, L. A., Thomas, B. C., Sharon, I., Castelle, C. J., Singh, A., et al. (2015). Unusual biology across a group comprising more than $15 \%$ of domain bacteria. Nature 523, 208-211. doi: 10.1038/nature14486

Brum, J. R., Ignacio-Espinoza, J. C., Roux, S., Doulcier, G., Acinas, S. G., Alberti, A., et al. (2015). Ocean plankton. Patterns and ecological drivers of ocean viral communities. Science 348:1261498. doi: 10.1126/science.1261498

Bryant, J. A., Aylward, F. O., Eppley, J. M., Karl, D. M., Church, M. J., and DeLong, E. F. (2015). Wind and sunlight shape microbial diversity in surface waters of the North Pacific Subtropical Gyre. ISME J. doi: 10.1038/ismej.2015.221. [Epub ahead of print].

Buchan, A., LeCleir, G. R., Gulvik, C. A., and González, J. M. (2014). Master recyclers: features and functions of bacteria associated with phytoplankton blooms. Nat. Rev. Microbiol. 12, 686-698. doi: 10.1038/nrmicro3326

Burke, C., Steinberg, P., Rusch, D., Kjelleberg, S., and Thomas, T. (2011a). Bacterial community assembly based on functional genes rather than species. Proc. Natl. Acad. Sci. U.S.A. 108, 14288-14293. doi: 10.1073/pnas.1101591108

Burke, C., Thomas, T., Lewis, M., Steinberg, P., and Kjelleberg, S. (2011b). Composition, uniqueness and variability of the epiphytic bacterial community 
of the green alga Ulva australis. ISME J. 5, 590-600. doi: 10.1038/ismej. 2010.164

Camacho, C., Coulouris, G., Avagyan, V., Ma, N., Papadopoulos, J., Bealer, K., et al. (2009). BLAST+: architecture and applications. BMC Bioinformatics 10:421. doi: 10.1186/1471-2105-10-421

Campbell, A. H., Marzinelli, E. M., Gelber, J., and Steinberg, P. D. (2015). Spatial variability of microbial assemblages associated with a dominant habitatforming seaweed. Front. Microbiol. 6:230. doi: 10.3389/fmicb.2015.00230

Carini, P., Campbell, E. O., Morré, J., Sañudo-Wilhelmy, S. A., Thrash, J. C., Bennett, S. E., et al. (2014). Discovery of a SAR11 growth requirement for thiamin's pyrimidine precursor and its distribution in the Sargasso Sea. ISME J. 8, 1727-1738. doi: 10.1038/ismej.2014.61

Caron, D. A., Countway, P. D., Jones, A. C., Kim, D. Y., and Schnetzer, A. (2012). Marine protistan diversity. Ann. Rev. Mar. Sci. 4, 467-493. doi: 10.1146/annurev-marine-120709-142802

Cavalier-Smith, T. (2006). Cell evolution and Earth history: stasis and revolution. Philos. Trans. R. Soc. Lond. B Biol. Sci. 361, 969-1006. doi: 10.1098/rstb.2006.1842

Chaffron, S., Rehrauer, H., Pernthaler, J., and von Mering, C. (2010). A global network of coexisting microbes from environmental and whole-genome sequence data. Genome Res. 20, 947-959. doi: 10.1101/gr.104521.109

Chow, C. E., Kim, D. Y., Sachdeva, R., Caron, D. A., and Fuhrman, J. A. (2014). Top-down controls on bacterial community structure: microbial network analysis of bacteria, T4-like viruses and protists. ISME J. 8, 816-829. doi: $10.1038 /$ ismej.2013.199

Chow, C. E., Sachdeva, R., Cram, J. A., Steele, J. A., Needham, D. M., Patel, A., et al. (2013). Temporal variability and coherence of euphotic zone bacterial communities over a decade in the Southern California Bight. ISME J. 7, 2259-2273. doi: 10.1038/ismej.2013.122

Chust, G., Irigoien, X., Chave, J., and Harris, R. P. (2013). Latitudinal phytoplankton distribution and the neutral theory of biodiversity. Glob. Ecol. Biogeogr. 22, 531-543. doi: 10.1111/geb.12016

Clarke, K. R., and Gorley, R. N. (2015). PRIMER v7: User Manual/Tutorial. Plymouth: PRIMER-E Ltd.

Cram, J. A., Chow, C. E., Sachdeva, R., Needham, D. M., Parada, A. E., Steele, J. A., et al. (2015a). Seasonal and interannual variability of the marine bacterioplankton community throughout the water column over ten years. ISME J. 9, 563-580. doi: 10.1038/ismej.2014.153

Cram, J. A., Xia, L. C., Needham, D. M., Sachdeva, R., Sun, F., and Fuhrman, J. A. (2015b). Cross-depth analysis of marine bacterial networks suggests downward propagation of temporal changes. ISME J. 9, 2573-2586. doi: 10.1038/ismej.2015.76

Crespo, B. G., Pommier, T., Fernández-Gómez, B., and Pedrós-Alió, C. (2013). Taxonomic composition of the particle-attached and free-living bacterial assemblages in the Northwest Mediterranean Sea analyzed by pyrosequencing of the 16S rRNA. Microbiologyopen 2, 541-552. doi: 10.1002/mbo3.92

Crump, B. C., Armbrust, E. V., and Baross, J. A. (1999). Phylogenetic analysis of particle-attached and free-living bacterial communities in the Columbia river, its estuary, and the adjacent coastal ocean. Appl. Environ. Microbiol. 65, 3192-3204.

Dang, H., and Lowell, C. R. (2016). Microbial surface colonization and biofilm development in marine environments. Microbiol. Mol. Biol. Rev. 80, 91-138. doi: 10.1128/MMBR.00037-15

De Monte, S., Soccodato, A., Alvain, S., and d'Ovidio, F. (2013). Can we detect oceanic biodiversity hotspots from space? ISME J. 7, 2054-2056. doi: 10.1038/ismej.2013.72

de Vargas, C., Audic, S., Henry, N., Decelle, J., Mahe, F., Logares, R., et al. (2015). Ocean plankton. Eukaryotic plankton diversity in the sunlit ocean. Science 348:1261605. doi: 10.1126/science. 1261605

Decelle, J., Romac, S., Stern, R. F., Bendife, E. M., Zingone, A., Audic, S., et al. (2015). PhytoREF: a reference database of the plastidial 16S rRNA gene of photosynthetic eukaryotes with curated taxonomy. Mol. Ecol. Resour. 15, 1435-1445. doi: 10.1111/1755-0998.12401

DeLong, E. F., Franks, D. G., and Alldredge, I. L. (1993). Phylogenetic diversity of aggregate-attached vs. free-living marine bacterial assemblages. Limnol. Oceanogr. 38, 924-934. doi: 10.4319/lo.1993.38.5.0924

Dittami, S. M., Duboscq-Bidot, L., Perennou, M., Gobet, A., Corre, E., Boyen, C., et al. (2016). Host-microbe interactions as a driver of acclimation to salinity gradients in brown algal cultures. ISME J. 10, 51-63. doi: 10.1038/ismej.2015.104

Dupont, C. L., Rusch, D. B., Yooseph, S., Lombardo, M. J., Richter, R. A., Valas, R., et al. (2012). Genomic insights to SAR86, an abundant and uncultivated marine bacterial lineage. ISME J. 6, 1186-1199. doi: 10.1038/ismej.2011.189

Eiler, A., Hayakawa, D. H., and Rappé, M. S. (2011). Non-random assembly of bacterioplankton communities in the subtropical north pacific ocean. Front. Microbiol. 2:140. doi: 10.3389/fmicb.2011.00140

Eiler, A., Heinrich, F., and Bertilsson, S. (2012). Coherent dynamics and association networks among lake bacterioplankton taxa. ISME J. 6, 330-342. doi: 10.1038/ismej.2011.113

Falkowski, P. G., Fenchel, T., and Delong, E. F. (2008). The microbial engines that drive Earth's biogeochemical cycles. Science 320, 1034-1039. doi: $10.1126 /$ science. 1153213

Faust, K., and Raes, J. (2012). Microbial interactions: from networks to models. Nat. Rev. Microbiol. 10, 538-550. doi: 10.1038/nrmicro2832

Faust, K., Lahti, L., Gonze, D., de Vos, W. M., and Raes, J. (2015a). Metagenomics meets time series analysis: unraveling microbial community dynamics. Curr. Opin. Microbiol. 25, 56-66. doi: 10.1016/j.mib.2015.04.004

Faust, K., Lima-Mendez, G., Lerat, J. S., Sathirapongsasuti, J. F., Knight, R., Huttenhower, C., et al. (2015b). Cross-biome comparison of microbial association networks. Front. Microbiol. 6:1200. doi: 10.3389/fmicb.2015. 01200

Fontanez, K. M., Eppley, J. M., Samo, T. J., Karl, D. M., and DeLong, E. F. (2015). Microbial community structure and function on sinking particles in the North Pacific Subtropical Gyre. Front. Microbiol. 6:469. doi: 10.3389/fmicb.2015.00469

Freilich, S., Zarecki, R., Eilam, O., Segal, E. S., Henry, C. S., Kupiec, M., et al. (2011). Competitive and cooperative metabolic interactions in bacterial communities. Nat. Commun. 2, 589. doi: 10.1038/ncomms1597

Freitas, S., Hatosy, S., Fuhrman, J. A., Huse, S. M., Welch, D. B., Sogin, M. L., et al. (2012). Global distribution and diversity of marine Verrucomicrobia. ISME J. 6, 1499-1505. doi: 10.1038/ismej.2012.3

Friedline, C. J., Franklin, R. B., McCallister, S. L., and Rivera, M. C. (2012). Bacterial assemblages of the eastern Atlantic Ocean reveal both vertical and latitudinal biogeographic signatures. Biogeosciences 9, 2177-2193. doi: 10.5194/bg-9-21772012

Friedman, J., and Alm, E. J. (2012). Inferring correlation networks from genomic survey data. PLoS Comput. Biol. 8:e1002687. doi: 10.1371/journal.pcbi.1002687

Fuhrman, J. A., Cram, J. A., and Needham, D. M. (2015). Marine microbial community dynamics and their ecological interpretation. Nat. Rev. Microbiol. 13, 133-146. doi: 10.1038/nrmicro3417

Ganesh, S., Parris, D. J., DeLong, E. F., and Stewart, F. J. (2014). Metagenomic analysis of size-fractionated picoplankton in a marine oxygen minimum zone. ISME J. 8, 187-211. doi: 10.1038/ismej.2013.144

Garcia, S. L., Buck, M., McMahon, K. D., Grossart, H. P., Eiler, A., and Warnecke, F. (2015). Auxotrophy and intra-population complementary in the 'interactome' of a cultivated freshwater model community. Mol. Ecol. 24, 4449-4459. doi: $10.1111 / \mathrm{mec} .13319$

Ghai, R., Mizuno, C. M., Picazo, A., Camacho, A., and Rodriguez-Valera, F. (2013). Metagenomics uncovers a new group of low GC and ultra-small marine Actinobacteria. Sci. Rep. 3:2471. doi: 10.1038/srep02471

Giebel, H. A., Kalhoefer, D., Gahl-Janssen, R., Choo, Y. J., Lee, K., Cho, J. C., et al. (2013). Planktomarina temperata gen. nov., sp. nov., belonging to the globally distributed RCA cluster of the marine Roseobacter clade, isolated from the German Wadden Sea. Int. J. Syst. Evol. Microbiol. 63, 4207-4217. doi: 10.1099/ijs.0.053249-0

Giering, S. L., Sanders, R., Lampitt, R. S., Anderson, T. R., Tamburini, C., Boutrif, M., et al. (2014). Reconciliation of the carbon budget in the ocean's twilight zone. Nature 507, 480-483. doi: 10.1038/nature13123

Gilbert, J. A., Steele, J. A., Caporaso, J. G., Steinbrück, L., Reeder, J., Temperton, B., et al. (2012). Defining seasonal marine microbial community dynamics. ISME J. 6, 298-308. doi: 10.1038/ismej.2011.107

Giovannoni, S. J. (2012). Vitamins in the sea. Proc. Natl. Acad. Sci. U.S.A. 109, 13888-13889. doi: 10.1073/pnas.1211722109

Giovannoni, S. J., Cameron, T. J., and Temperton, B. (2014). Implications of streamlining theory for microbial ecology. ISME J. 8, 1553-1565. doi: 10.1038/ismej.2014.60 
Gómez-Pereira, P. R., Schüler, M., Fuchs, B. M., Bennke, C., Teeling, H., Waldmann, J., et al. (2012). Genomic content of uncultured Bacteroidetes from contrasting oceanic provinces in the North Atlantic Ocean. Environ. Microbiol. 14, 52-66. doi: 10.1111/j.1462-2920.2011.02555.x

Grote, J., Thrash, J. C., Huggett, M. J., Landry, Z. C., Carini, P., Giovannoni, S. J., et al. (2012). Streamlining and core genome conservation among highly divergent members of the SAR11 clade. MBio 3, e00252-e00212. doi: 10.1128/mbio.00252-12

Guidi, L., Chaffron, S., Bittner, L., Eveillard, D., Larhlimi, A., Roux, S., et al. (2016). Plankton networks driving carbon export in the oligotrophic ocean. Nature 532, 465-470. doi: 10.1038/nature16942

Hartmann, M., Grob, C., Tarran, G. A., Martin, A. P., Burkill, P. H., Scanlan, D. J., et al. (2012). Mixotrophic basis of Atlantic oligotrophic ecosystems. Proc. Natl. Acad. Sci. U.S.A. 109, 5756-5760. doi: 10.1073/pnas.1118179109

Hartmann, M., Zubkov, M. V., Scanlan, D. J., and Lepère, C. (2013). In situ interactions between photosynthetic picoeukaryotes and bacterioplankton in the Atlantic Ocean: evidence for mixotrophy. Environ. Microbiol. Rep. 5, 835-840. doi: 10.1111/1758-2229.12084

Herndl, G. J., and Reinthaler, T. (2013). Microbial control of the dark end of the biological pump. Nat. Geosci. 6, 718-724. doi: 10.1038/ngeo1921

Hibbing, M. E., Fuqua, C., Parsek, M. R., and Peterson, S. B. (2010). Bacterial competition: surviving and thriving in the microbial jungle. Nat. Rev. Microbiol. 8, 15-25. doi: 10.1038/nrmicro2259

Ju, F., Xia, Y., Guo, F., Wang, Z., and Zhang, T. (2014). Taxonomic relatedness shapes bacterial assembly in activated sludge of globally distributed wastewater treatment plants. Environ. Microbiol. 16, 2421-2432. doi: 10.1111/14622920.12355

Kirkham, A. R., Jardillier, L. E., Tiganescu, A., Pearman, J., Zubkov, M. V., and Scanlan, D. J. (2011). Basin-scale distribution patterns of photosynthetic picoeukaryotes along an Atlantic Meridional Transect. Environ. Microbiol. 13, 975-990. doi: 10.1111/j.1462-2920.2010.02403.x

Kirkham, A. R., Lepère, C., Jardillier, L. E., Not, F., Bouman, H., Mead, A., et al. (2013). A global perspective on marine photosynthetic picoeukaryote community structure. ISME J. 7, 922-936. doi: 10.1038/ismej.2012.166

Klindworth, A., Pruesse, E., Schweer, T., Peplies, J., Quast, C., Horn, M., et al. (2013). Evaluation of general 16S ribosomal RNA gene PCR primers for classical and next-generation sequencing-based diversity studies. Nucleic Acids Res. 41, el. doi: 10.1093/nar/gks808

Kostka, J. E., Prakash, O., Overholt, W. A., Green, S. J., Freyer, G., Canion, A., et al. (2011). Hydrocarbon-degrading bacteria and the bacterial community response in gulf of Mexico beach sands impacted by the deepwater horizon oil spill. Appl. Environ. Microbiol. 77, 7962-7974. doi: 10.1128/AEM.05402-11

Krupke, A., Mohr, W., LaRoche, J., Fuchs, B. M., Amann, R. I., and Kuypers, M. M. (2015). The effect of nutrients on carbon and nitrogen fixation by the UCYNA-haptophyte symbiosis. ISME J. 9, 1635-1647. doi: 10.1038/ismej.2014.253

Lima-Mendez, G., Faust, K., Henry, N., Decelle, J., Colin, S., Carcillo, F., et al. (2015). Ocean plankton. Determinants of community structure in the global plankton interactome. Science 348, 1262073. doi: 10.1126/science.1262073

Liu, H., Probert, I., Uitz, J., Claustre, H., Aris-Brosou, S., Frada, M., et al. (2009). Extreme diversity in noncalcifying haptophytes explains a major pigment paradox in open oceans. Proc. Natl. Acad. Sci. U.S.A. 106, 12803-12808. doi: 10.1073/pnas.0905841106

Longhurst, A. (1998). Ecological Geography of the Sea. London: Academic Press.

Marzinelli, E. M., Williams, S. B., Babcock, R. C., Barrett, N. S., Johnson, C. R., Jordan, A., et al. (2015). Large-scale geographic variation in distribution and abundance of Australian deep-water kelp forests. PLOS ONE 10:e0118390. doi: 10.1371/journal.pone.0118390

Meyer, P. E., Lafitte, F., and Bontempi, G. (2008). minet: A R/Bioconductor package for inferring large transcriptional networks using mutual information. BMC Bioinformatics 9:461. doi: 10.1186/1471-2105-9-461

Milici, M., Tomasch, J., Wos-Oxley, M. L., Decelle, J., Jauregui, R., Wang, H., et al. (2016a). Bacterioplankton biogeography in the Atlantic Ocean: a case of study of the distance-decay relationship. Front. Microbiol. 7:590. doi: 10.3389/fmicb. 2016.00590

Milici, M., Tomasch, J., Wos-Oxley, M. L., Wang, H., Jáuregui, R., CamarinhaSilva, A., et al. (2016b). Low diversity of planktonic bacteria in the tropical ocean. Sci. Rep. 6:19054. doi: 10.1038/srep19054
Mohit, V., Archambault, P., Toupoint, N., and Lovejoy, C. (2014). Phylogenetic differences in attached and free-living bacterial communities in a temperate coastal lagoon during summer, revealed via high-throughput 16S rRNA gene sequencing. Appl. Environ. Microbiol. 80, 2071-2083. doi: 10.1128/AEM.0 2916-13

Moran, M. A., Reisch, C. R., Kiene, R. P., and Whitman, W. B. (2012). Genomic insights into bacterial DMSP transformations. Ann. Rev. Mar. Sci. 4, 523-542. doi: 10.1146/annurev-marine-120710-100827

Morris, J. J., Lenski, R. E., and Zinser, E. R. (2012). The Black Queen Hypothesis: evolution of dependencies through adaptive gene loss. MBio 3, e00036-e00012. doi: $10.1128 / \mathrm{mBio} .00036-12$

Morris, R. M., Frazar, C. D., and Carlson, C. A. (2012). Basin-scale patterns in the abundance of SAR11 subclades, marine Actinobacteria (OM1), members of the Roseobacter clade and OCS116 in the South Atlantic. Environ. Microbiol. 14, 1133-1144. doi: 10.1111/j.1462-2920.2011.02694.x

Morris, R. M., Rappé, M. S., Connon, S. A., Vergin, K. L., Siebold, W. A., Carlson, C. A., et al. (2002). SAR11 clade dominates ocean surface bacterioplankton communities. Nature 420, 806-810. doi: 10.1038/nature01240

Needham, D. M., and Fuhrman, J. A. (2016). Pronounced daily succession of phytoplankton, archaea and bacteria following a spring bloom. Nat. Microbiol. 1:16005. doi: 10.1038/nmicrobiol.2016.5

Padilla, C. C., Ganesh, S., Gantt, S., Huhman, A., Parris, D. J., Sarode, N., et al. (2015). Standard filtration practices may significantly distort planktonic microbial diversity estimates. Front. Microbiol. 6:547. doi: 10.3389/fmicb.2015.00547

Peura, S., Bertilsson, S., Jones, R. I., and Eiler, A. (2015). Resistant microbial cooccurrence patterns inferred by network topology. Appl. Environ. Microbiol. 81, 2090-2097. doi: 10.1128/AEM.03660-14

Pizzetti, I., Fuchs, B. M., Gerdts, G., Wichels, A., Wiltshire, K. H., and Amann, R. (2011). Temporal variability of coastal Planctomycetes clades at Kabeltonne station, North Sea. Appl. Environ. Microbiol. 77, 5009-5017. doi: 10.1128/AEM.02931-10

Pruesse, E., Peplies, J., and Glöckner, F. O. (2012). SINA: accurate high-throughput multiple sequence alignment of ribosomal RNA genes. Bioinformatics 28, 1823-1829. doi: 10.1093/bioinformatics/bts252

Pruesse, E., Quast, C., Knittel, K., Fuchs, B. M., Ludwig, W., Peplies, J., et al. (2007). SILVA: a comprehensive online resource for quality checked and aligned ribosomal RNA sequence data compatible with ARB. Nucleic Acids Res. 35, 7188-7196. doi: 10.1093/nar/gkm864

Reygondeau, G., Longhurst, A., Martinez, E., Beaugrand, G., Antoine, D., and Maury, O. (2013). Dynamic biogeochemical provinces in the global ocean. Global Biogeochem. Cycles 27, 1046-1058. doi: 10.1002/gbc.20089

Rieck, A., Herlemann, D. P., Jürgens, K., and Grossart, H. P. (2015). Particleassociated differ from free-living bacteria in surface waters of the Baltic Sea. Front. Microbiol. 6:1297. doi: 10.3389/fmicb.2015.01297

Rusch, D. B., Halpern, A. L., Sutton, G., Heidelberg, K. B., Williamson, S., Yooseph, S., et al. (2007). The Sorcerer II global ocean sampling expedition: northwest Atlantic through eastern tropical Pacific. PLoS Biol. 5:e77. doi: 10.1371/journal.pbio.0050077

Salazar, G., Cornejo-Castillo, F. M., Benítez-Barrios, V., Fraile-Nuez, E., ÁlvarezSalgado, X. A., Duarte, C. M., et al. (2016). Global diversity and biogeography of deep-sea pelagic prokaryotes. ISME J. 10, 596-608. doi: 10.1038/ismej.2015.137

Salazar, G., Cornejo-Castillo, F. M., Borrull, E., Díez-Vives, C., Lara, E., Vaqué, D., et al. (2015). Particle-association lifestyle is a phylogenetically conserved trait in bathypelagic prokaryotes. Mol. Ecol. 24, 5692-5706. doi: 10.1111/mec.13419

Sale, P. F. (1979). Recruitment, loss and coexistence in a guild of territorial coral reef fishes. Oecologia 42, 159-177. doi: 10.1007/BF00344855

Sañudo-Wilhelmy, S. A., Gómez-Consarnau, L., Suffridge, C., and Webb, E. A. (2014). The role of B vitamins in marine biogeochemistry. Ann. Rev. Mar. Sci. 6, 339-367. doi: 10.1146/annurev-marine-120710-100912

Satinsky, B. M., Crump, B. C., Smith, C. B., Sharma, S., Zielinski, B. L., Doherty, M., et al. (2014). Microspatial gene expression patterns in the Amazon River Plume. Proc. Natl. Acad. Sci. U.S.A. 111, 11085-11090. doi: 10.1073/pnas.1402782111

Schattenhofer, M., Fuchs, B. M., Amann, R., Zubkov, M. V., Tarran, G. A., and Pernthaler, J. (2009). Latitudinal distribution of prokaryotic picoplankton populations in the Atlantic Ocean. Environ. Microbiol. 11, 2078-2093. doi: 10.1111/j.1462-2920.2009.01929.x 
Seyedsayamdost, M. R., Case, R. J., Kolter, R., and Clardy, J. (2011). The Jekylland-Hyde chemistry of Phaeobacter gallaeciensis. Nat. Chem. 3, 331-335. doi: 10.1038/nchem.1002

Shannon, P., Markiel, A., Ozier, O., Baliga, N. S., Wang, J. T., Ramage, D., et al. (2003). Cytoscape: a software environment for integrated models of biomolecular interaction networks. Genome Res. 13, 2498-2504. doi: 10.1101/gr.1239303

Simon, H. M., Smith, M. W., and Herfort, L. (2014). Metagenomic insights into particles and their associated microbiota in a coastal margin ecosystem. Front. Microbiol. 5:466. doi: 10.3389/fmicb.2014.00466

Smith, M. W., Zeigler, A. L., Allen, A. E., Herfort, L., and Simon, H. M. (2013). Contrasting genomic properties of free-living and particle-attached microbial assemblages within a coastal ecosystem. Front. Microbiol. 4:120. doi: $10.3389 /$ fmicb. 2013.00120

Stocker, R., and Seymour, J. R. (2012). Ecology and physics of bacterial chemotaxis in the ocean. Microbiol. Mol. Biol. Rev. 76, 792-812. doi: 10.1128/MMBR.00029-12

Sunagawa, S., Coelho, L. P., Chaffron, S., Kultima, J. R., Labadie, K., Salazar, G., et al. (2015). Ocean plankton. Structure and function of the global ocean microbiome. Science 348:1261359. doi: 10.1126/science.1261359

Suttle, C. A. (2005). Viruses in the sea. Nature 437, 356-361. doi: 10.1038 /nature 04160

Swan, B. K., Tupper, B., Sczyrba, A., Lauro, F. M., Martinez-Garcia, M., González, J. M., et al. (2013). Prevalent genome streamlining and latitudinal divergence of planktonic bacteria in the surface ocean. Proc. Natl. Acad. Sci. U.S.A. 110, 11463-11468. doi: 10.1073/pnas.1304246110

Tamura, K., Stecher, G., Peterson, D., Filipski, A., and Kumar, S. (2013). MEGA6: molecular evolutionary genetics analysis version 6.0. Mol. Biol. Evol. 30, 2725-2729. doi: 10.1093/molbev/mst197

Teeling, H., Fuchs, B. M., Becher, D., Klockow, C., Gardebrecht, A., Bennke, C. M., et al. (2012). Substrate-controlled succession of marine bacterioplankton populations induced by a phytoplankton bloom. Science 336, 608-611. doi: $10.1126 /$ science. 1218344

Thompson, A. W., Foster, R. A., Krupke, A., Carter, B. J., Musat, N., Vaulot, D., et al. (2012). Unicellular cyanobacterium symbiotic with a single-celled eukaryotic alga. Science 337, 1546-1550. doi: 10.1126/science.1222700

Tripp, H. J., Kitner, J. B., Schwalbach, M. S., Dacey, J. W., Wilhelm, L. J., and Giovannoni, S. J. (2008). SAR11 marine bacteria require exogenous reduced sulphur for growth. Nature 452, 741-744. doi: 10.1038/nature06776

Vergin, K. L., Done, B., Carlson, C. A., and Giovannoni, S. J. (2013). Spatiotemporal distributions of rare bacterioplankton populations indicate adaptive strategies in the oligotrophic ocean. Aquat. Microb. Ecol. 71, 1-13. doi: 10.3354/ame01661
Voget, S., Wemheuer, B., Brinkhoff, T., Vollmers, J., Dietrich, S., Giebel, H. A., et al. (2015). Adaptation of an abundant Roseobacter RCA organism to pelagic systems revealed by genomic and transcriptomic analyses. ISME J. 9, 371-384. doi: 10.1038/ismej.2014.134

Wagner-Döbler, I., Ballhausen, B., Berger, M., Brinkhoff, T., Buchholz, I., Bunk, B., et al. (2010). The complete genome sequence of the algal symbiont Dinoroseobacter shibae: a hitchhiker's guide to life in the sea. ISME J. 4, 61-77. doi: 10.1038/ismej.2009.94

Wang, H., Tomasch, J., Jarek, M., and Wagner-Döbler, I. (2014). A dual-species co-cultivation system to study the interactions between Roseobacters and dinoflagellates. Front. Microbiol. 5:311. doi: 10.3389/fmicb.2014.00311

Wemheuer, B., Güllert, S., Billerbeck, S., Giebel, H. A., Voget, S., Simon, M., et al. (2014). Impact of a phytoplankton bloom on the diversity of the active bacterial community in the southern North Sea as revealed by metatranscriptomic approaches. FEMS Microbiol. Ecol. 87, 378-389. doi: 10.1111/1574-6941. 12230

Whitman, W. B., Coleman, D. C., and Wiebe, W. J. (1998). Prokaryotes: the unseen majority. Proc. Natl. Acad. Sci. U.S.A. 95, 6578-6583. doi: 10.1073/pnas.95.12.6578

Zehr, J. P., and Kudela, R. M. (2011). Nitrogen cycle of the open ocean: from genes to ecosystems. Ann. Rev. Mar. Sci. 3, 197-225. doi: 10.1146/annurev-marine120709-142819

Zeigler, A. L., Allen, E. E., Badger, J. H., McCrow, J. P., Paulsen, I. T., Elbourne, L. D., et al. (2012). Influence of nutrients and currents on the genomic composition of microbes across an upwelling mosaic. ISME J. 6, 1403-1414. doi: 10.1038/ismej.2011.201

Zelezniak, A., Andrejev, S., Ponomarova, O., Mende, D. R., Bork, P., and Patil, K. R. (2015). Metabolic dependencies drive species co-occurrence in diverse microbial communities. Proc. Natl. Acad. Sci. U.S.A. 112, 6449-6454. doi: $10.1073 /$ pnas. 1421834112

Conflict of Interest Statement: The authors declare that the research was conducted in the absence of any commercial or financial relationships that could be construed as a potential conflict of interest.

Copyright (C) 2016 Milici, Deng, Tomasch, Decelle, Wos-Oxley, Wang, Jáuregui, Plumeier, Giebel, Badewien, Wurst, Pieper, Simon and Wagner-Döbler. This is an open-access article distributed under the terms of the Creative Commons Attribution License (CC BY). The use, distribution or reproduction in other forums is permitted, provided the original author(s) or licensor are credited and that the original publication in this journal is cited, in accordance with accepted academic practice. No use, distribution or reproduction is permitted which does not comply with these terms. 